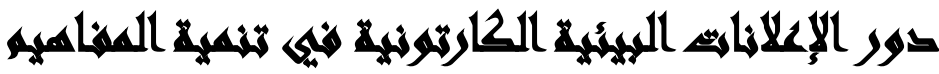

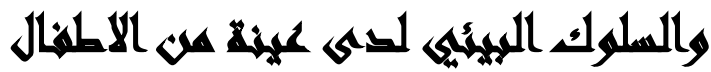

\section{$[1 v]$}

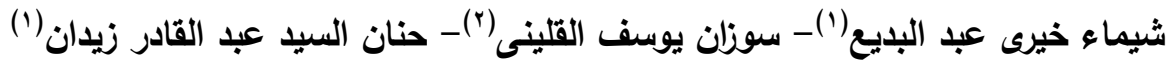

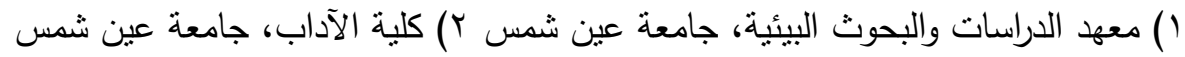

\section{المستخلص}

تعد هذه الدراسة من الدراسات الوصفية التحليلية التي يستخدم فيها منهج المسح بالعينة

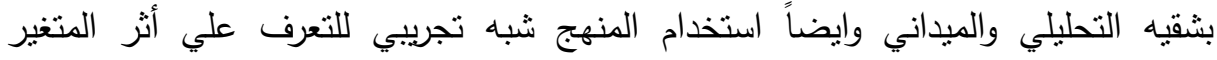

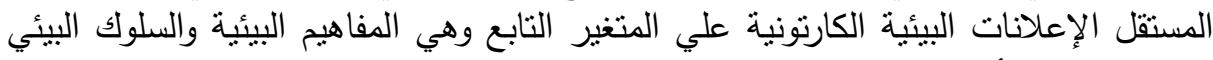

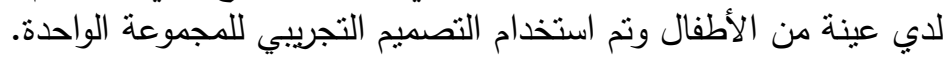

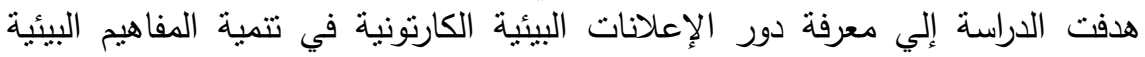

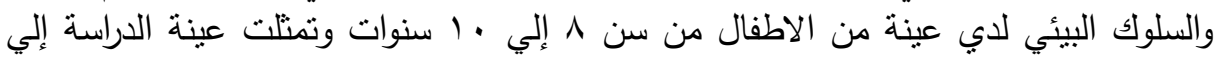

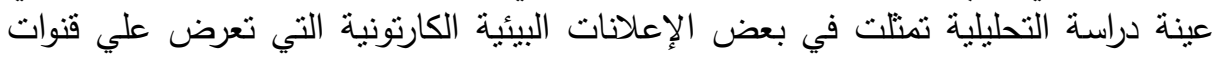

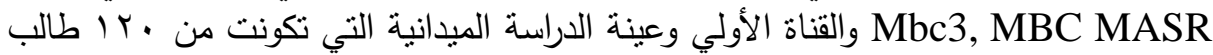

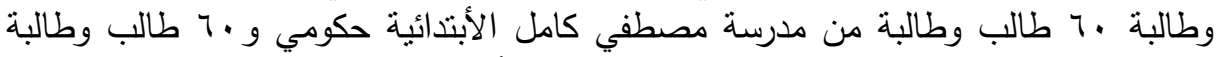

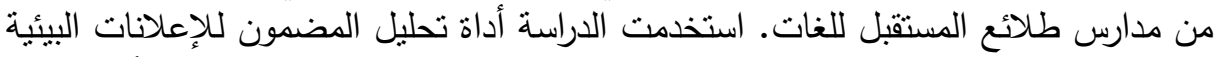

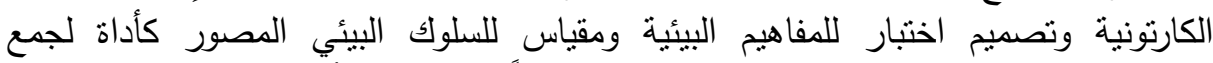

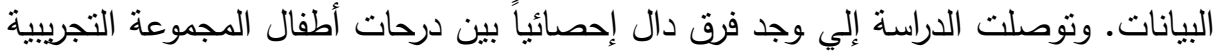

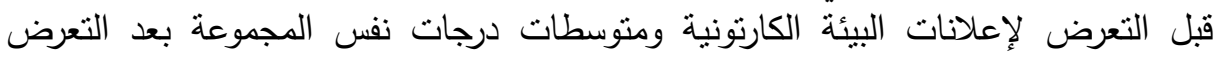

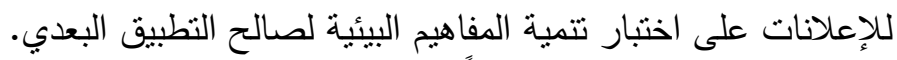

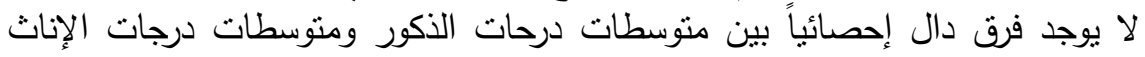

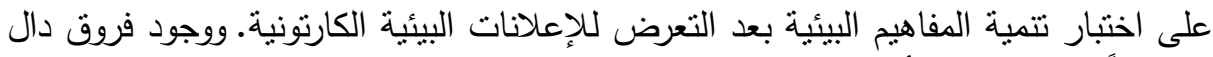

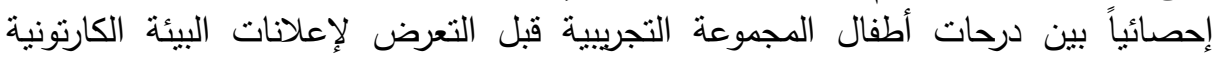

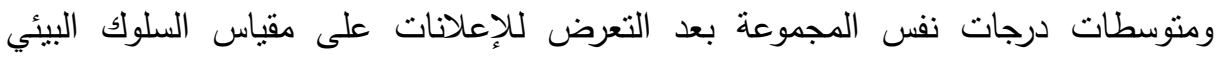

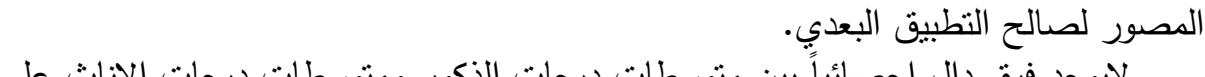

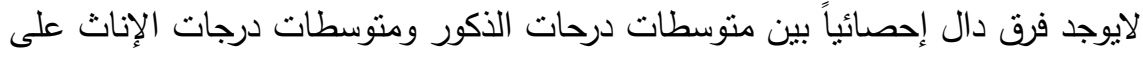

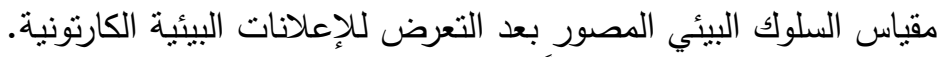

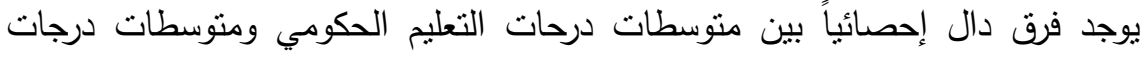

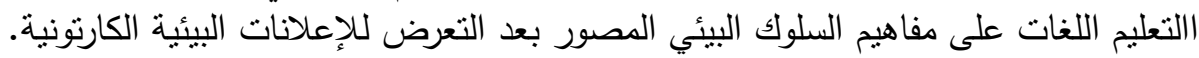

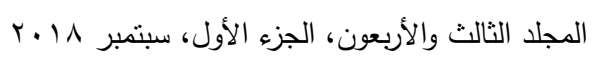




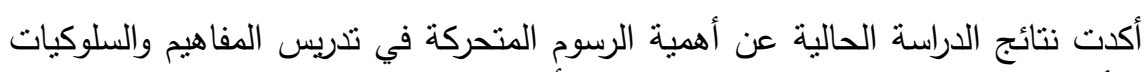

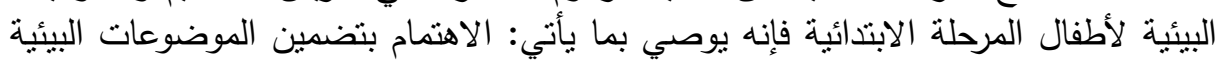

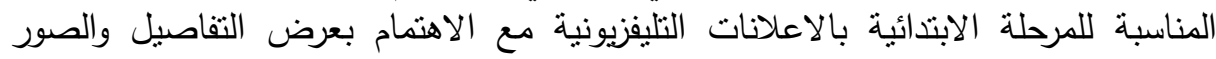

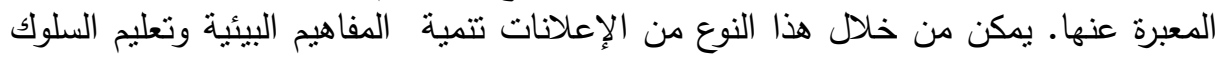

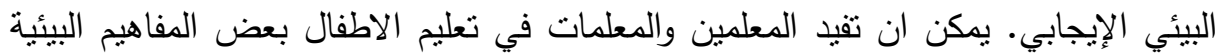

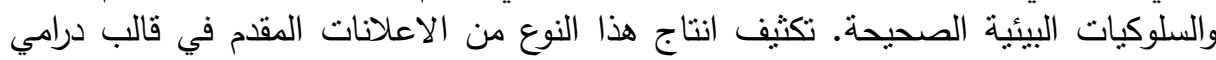

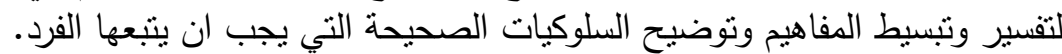
الكلمات المفتاحية: الإعلانات التليفزيونية، الإعلانات البيات البيئية، الإعلانات البات الكارتونية، المفاهيم البردية البيئية، السلوك البيئي، الأطفال. - البلات.

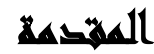

أصبحت وسائل الاعلام جزء لا يتجزأ من عمليتي التزبية والتتقيف كما أنها تمثل حجر

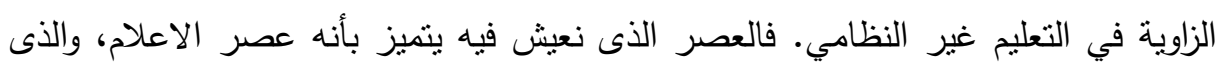

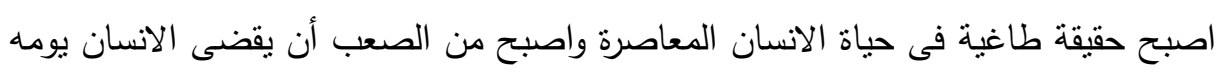

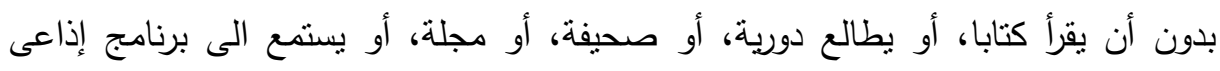
تلفزيونى او يشاهد برنامج تليفزيونى ويزداد هذا القول وضوحا إذا عرفنا أن وسائل الأعلام

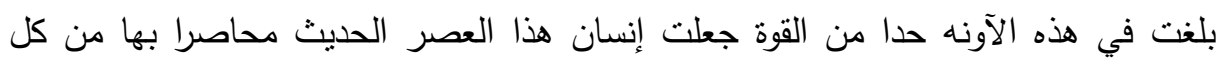

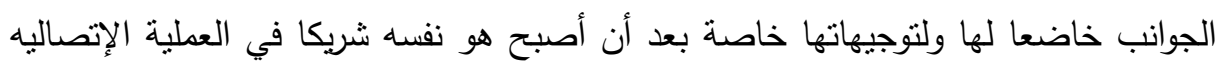
من خلال إعلام ثنائي الإتجاه قائم علي المشاركة وبذلك يتأثر الطفل بوسائل الاعلام المختلفه

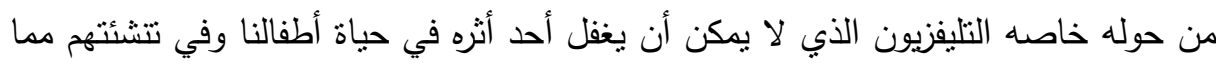
دعا الباحثين في مجال الاعلام إلى تسميته بالأب الثالث في حياة الاطفال فطفل اليوم منشئه الته

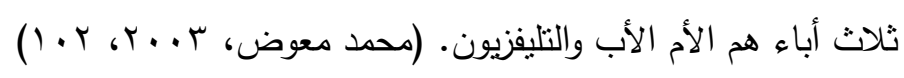

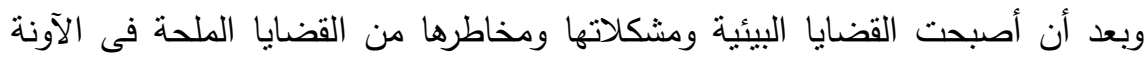

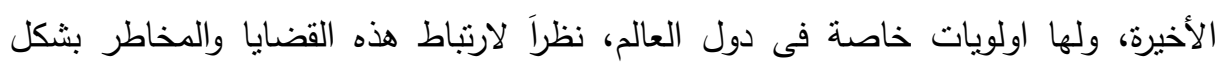

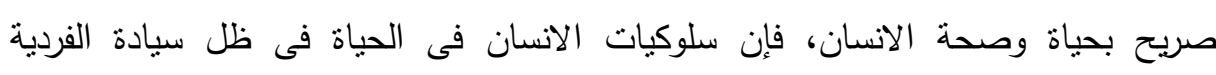

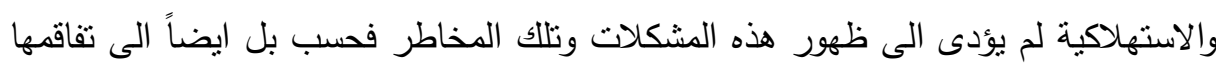

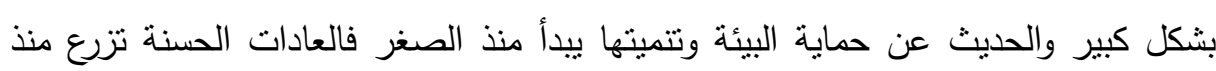


الطفولة، والبيئة والحفاظ عليها تقوم على مجموع من العادات الحسنة التى إن غرزت فى

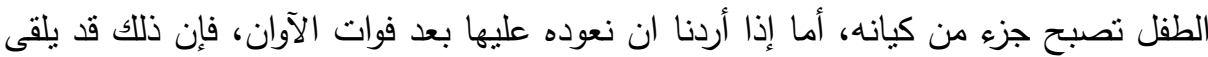
صعوبة ما، النظافة والحفاظ على المياة وتذوق الجمال، والحفاظ على جمال الطبيعة، وزراعة

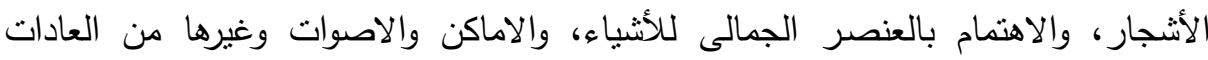
تصبح جزء لا يتجزأ من كيان الإنسان اذا ما اعتاد عليه من الصغر فعلينا اذا أن نبدأ بالطفل

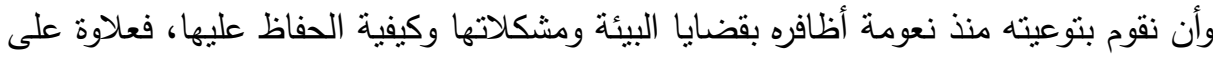

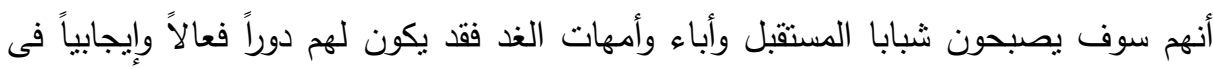
توعية الكبار من حولهم سواء كان هذا بشكل مباشر أو غير مباشر · (محمود عبد الجابر،

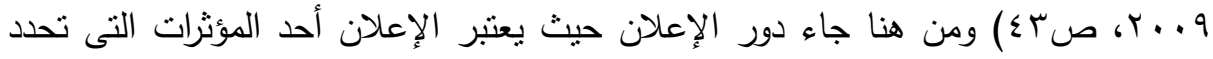

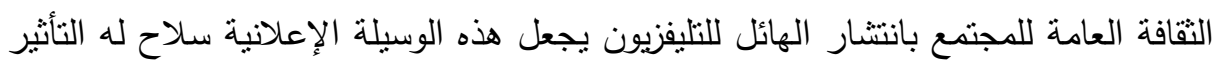
يستمد الإعلان منها مزيد من القوة فى إطار ثقافة الصورة المصحوبة بمؤثرات الصوت

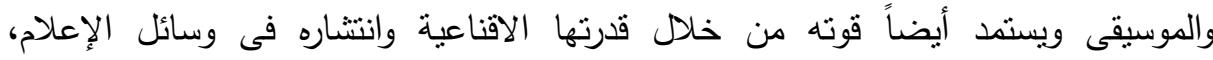
فالاعلان أصبح اليوم صناعة قائمة بذاتها تعددت طرائقه وتقتياته وأدواته ووظائفه حيث أصبح جزء مهم من حياتتا اليومية إذ أن تزايد أهمية ودور وسائل الإعلان فى حياتتا اليومية يجعل

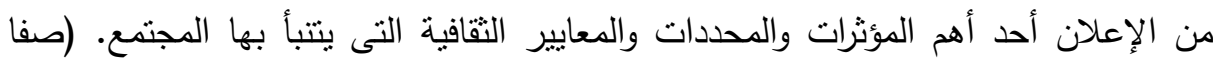

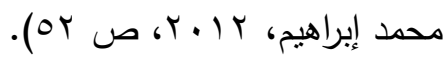

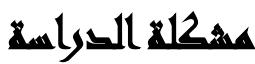

ومن خلال استعراض بعض الدراسات السابقة العربية والأجنبية منل دراسة (مطهر على

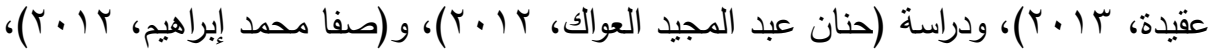

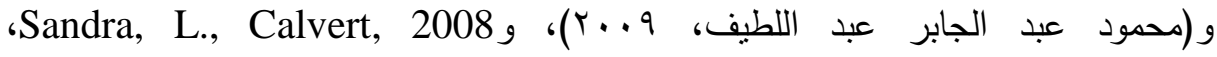
2008 Shaebier, Kirmani الطفل والاعلانات التليفزيونية. ولكن معظم هذه الدراسات ركزت على السلوك الشرائى للطفل، الاجتماعي، النفسي، مستوى الطموح. 
وهناك العديد من الدراسات التى أكدت على دراسة المفاهيم والسلوك البيئى من جوانب متعددة ولكن لا يوجد دراسة تتاولتها من خلا الإعلانات البيئية الكارتونية، منل دراسة (اميرة

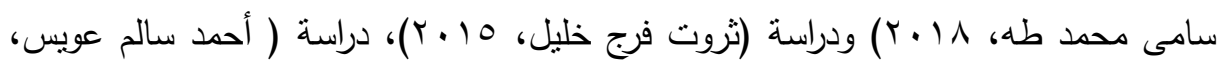

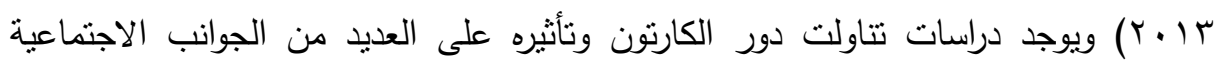

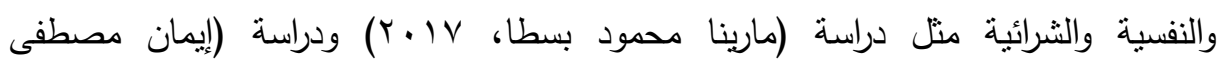

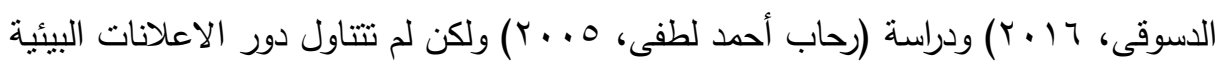
الكارتونية فى تتمية المفاهيم والسلوك البيئى.

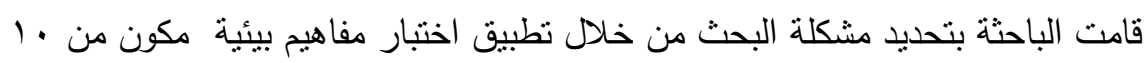

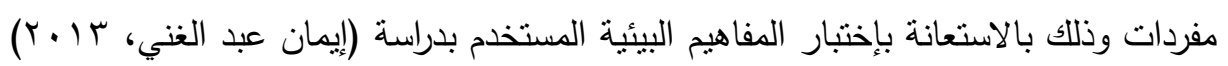

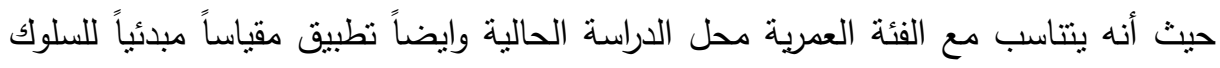
البيئي المصور مكون من 10 موقف مصور من خلال الاستعانة بمقياس البيئي المصور

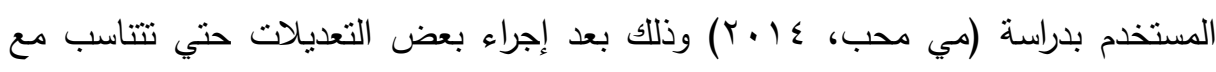

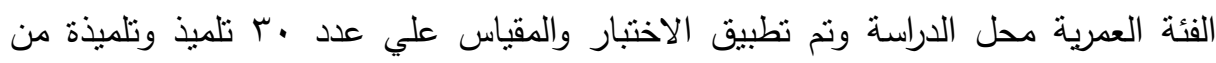
مدرسة طلائع المستقبل واسفرت النتيجة إلي الآتي: - ضعف مستوي المفاهيم البيئية عند الأطفال حيث بلغت متوسط الاثئ إجابتهم علي اختبار

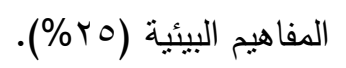

- ضعف مستوي السلوك البيئي حيث بلغ منوسط إجابتهم على مقياس السلوك البيئي .(\%ץ.)

وهذا يشير إلي تدني معرفة الأطفال بالدفاهيم البيئية والسلوك البيئي الصحيح بالنسبة للعينة الاستطلاعية. تعتبر الإعلانات التليفزيونية من أكثر الموضوعات لفتاً للنظر وجذباً لاهتمام الكبار والصغار لما لها من وسائل جذب متعددة وازدادت في الفترة الأخيرة ظهور الإعلانات الإجتماعية التي تتحدث عن الموضوعات البيئية مستخدمة الرسوم المتحركة التي تبسط

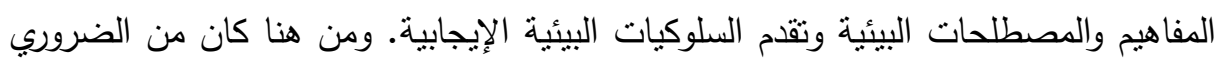


مجلة العلوم البيئية

معهد الدراسات والبحوث البيئية - جامعة عين شمس لئ

وجود دراسة علمية متخصصة تتناول دراسة الدور الذي تقوم بة الإعلانات البيئية الكارتونية في تتمية المفاهيم والسلوك البيئي الإيجابي لدي الأطفال.

\section{أسئلة التصواسما}

في محاولة للتصدي لهذة المشكلة ستحاول الدراسة الإجابة عن السؤال الرئيسي التالي: "ما دور الإعلانات البيئية الكارتونية فى تتمية المفاهيم والسلوك البيئى لاى عينة من البهن الأطفال؟" المور"

وينبثق من هذا السؤال الرئيس عدة أسئلة فرعية:

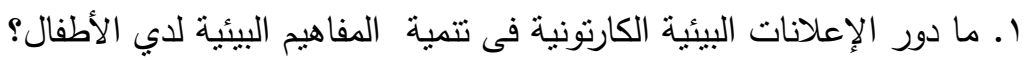

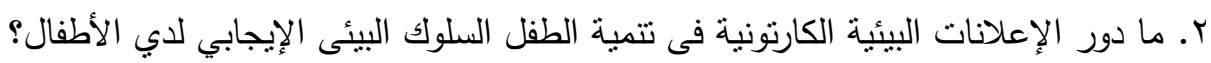

\section{أهمية الدراهـ}

الأهمية النظرية:

ا-نطور الدور الذى تؤديه الإعلانات البيئية الكارنونية فى عرض قضايا البيئة والأخطار التى تتعرض لها والتتبيه لمشاكلها والأخطار التى تهددها وتعليم الأطفال كيفية الحفاظ

$$
\text { عليها وتقديم النماذج القادرة على حمايتها وصونها. }
$$

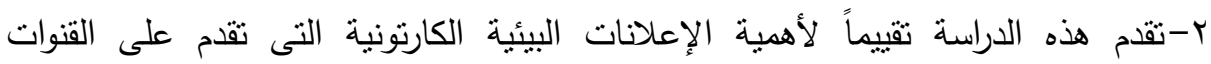
الفضائية وأثز تلك الإعلانات فى نشر المفاهيم البيئية وتعلم السلوك البيئى الصحيح لدى لإئي

$$
\text { الأطفال. }
$$

\section{الأهمية التطبيقية:}

1-يمكن أن تقيد فى إعداد اعلانات بيئية كارنونية يمكن من خلالها تتمية المفاهيم والسلوك

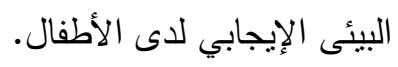

r-يمكن ان تفيد معلمى ومعلمات الأطفال فى تتمية الدفاهيم والسلوك البيئي الإيجابي بالاستعانة بالاعلانات البيئية الكارتونية.

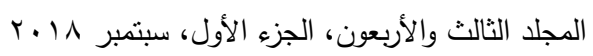


r-لفت نظر القائمين على دراسات وأبحاث الأطفال للاور الذى تلعب الاعلانات البيئية الكارنونية فى تتمية الدفاهيم والسلوك البيئي الإيجابي لديهم.

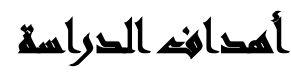

1-تحديد مدى تضمين الاعلانات البيئية الكارتونية للدفاهيم البيئية والسلوك البيئى.

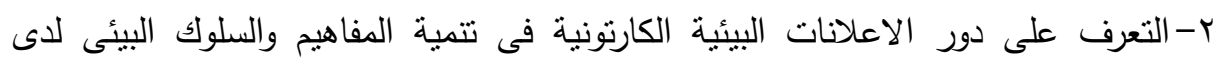
الأطفال.

r-الكثف عن الدور الذى تلعبه الإعلانات البيئية الكارتونية فى نشر المفاهيم وتعليم السلوك البيئى الصحيح لاى القائمين على إنتاج هذا النوع من الإعلانات.

\section{هزوض القراسما}

الفرض الأول: يوجد فرق دال إحصائياً بين متوسط درجات أطفال المجموعة التجريبية قبل

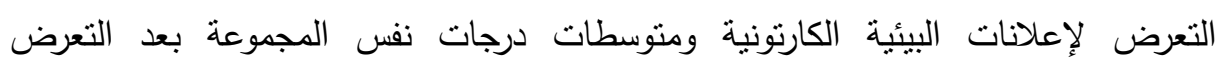
لإعلانات علي اختبار تتمية المفاهيم البيئية لصالح النطبيق البعدي.

الفرض الثاني: يوجد فرق دال إحصائياً بين منوسط درجات أطفال المجموعة التجريبية قبل التعرض للإعلانات البيئية الكارتونية علي مقياس السلوك البيئي المصور لصالح التطبيق البعدي. الفرض الثالث: يوجد فرق دال إحصائياً بين منوسطات درحات الذكور ومنوسطات درجات الإناث على مقياس السلوك البيئي المصور بعد التعرض للإعلانات البيئية الكارتونية.

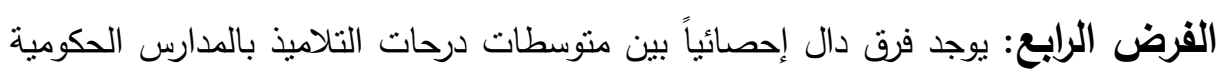

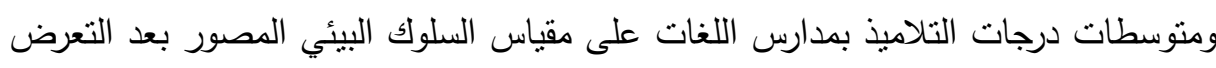
للإعلانات البيئية الكارنونية لصالح تعليم اللغات. الفرض الخامس: يوجد فرق دال إحصائياً بين متوسطات درحات التلاميذ بالددارس

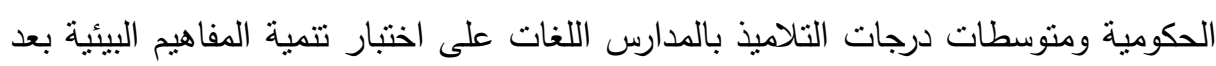
التعرض للإعلانات البيئية الكارتونية لصالح التعليم اللغات. 
الفرض السادس: يوجد فرق دال إحصائياً بين منوسط درحات أطفال المجموعة التجريبية قبل التعرض لإعلانات البيئة الكارنونية ومنوسطات درجات نفس المجموعة بعد التعرض

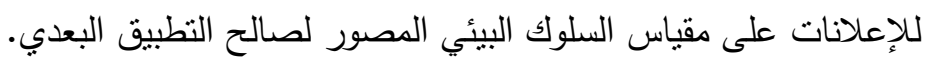

\section{همطلحمايت اللهيه}

الإعلان التلفزيونى: هو الثكل الفنى أو الرسالة المقدمة عن طريق التليفزيون للترويج لسلعة او خدمة تستخدم عناصر جذب وتأثير مثل اللون، الحركة والصوت، النماذج الكارتونية

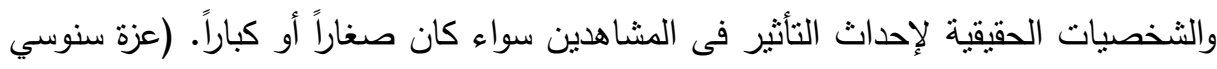

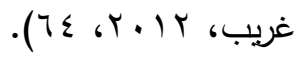
الرسوم المتحركة: هى شكل من الأشكال الفنية تعتمد على استحداث حركة من خلال عدد من اللقطات المتتابعة والمتلاحقة لقطة تلو الاخرى فى سرعة منتظمة، ويتم رسمها باليد أو الو بالكمبيوتر وقد اثتقتت هذه الكلمة من الكلمة الايطالية كارتون وتعنى الورق المقوى الذى ترسم

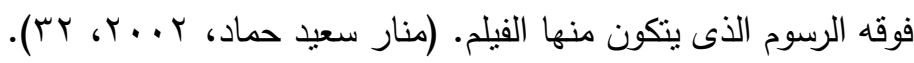
إعلان الكارتون: هى التى تعتمد تصوير الثخصيات المختلفة اما فى صورة حيوانات أو آدميين ولكن بطريقة فكاهية ولطيفة واعلانات الكارتون لا تمنل نوعاً مختلفاً من اعلانات التليفزيون بل هو اسلوب من الاساليب المتعددة التى يمكن للمعلن استخدامها. (محمد فريد

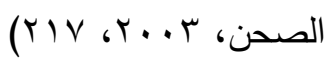

المفاهيم البيئية: تعرف على انها ادراك العلاقات الموجودة بين الظواهر أو الاحداث أو

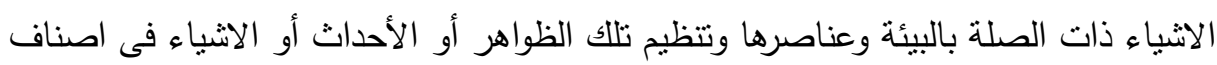

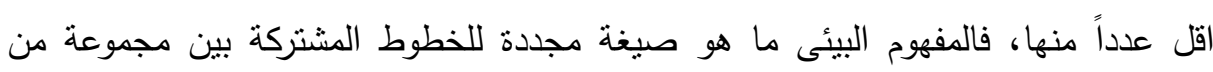

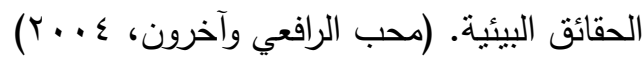
السلوك البيئى: يعرف السلوك البيئى كما تتاولته بعض الادبيات بأنه أى عمل أو تصرف جماعى موجه مباشر لعلاج أو لحل القضايا والمشكلات البيئة. 


\section{الدراسايت الساريخ}

دراسات تناولت الإعلانات التليفزيونية:

دراسة مصطفى سمير على أحمد(Y V . P): وعنوانها استخدامات المراهقين للإعلان

الإكترونى والإشباعات المتحققة منه.

هدفت الدراسة إلي معرفة الدور الذى يؤديه الإعلان عبر شبكة الإنترنت لإمداد المراهين

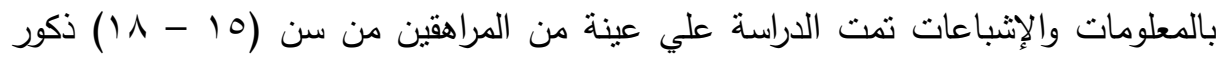

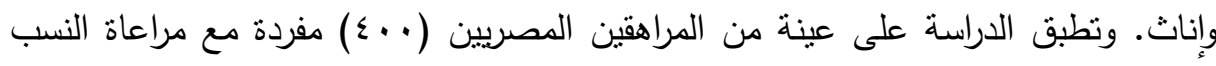
المتساوية للعوامل الديموجرافية بين (الذكور والإناث) من محافظة القاهرة والفيوم والجيزة والقليوبية.

ومن أهم نتائج الدراسة: جاء "الإنترنت" فى مقدمة ترتيب الوسائل الإعلانية التى نتاسب عينة

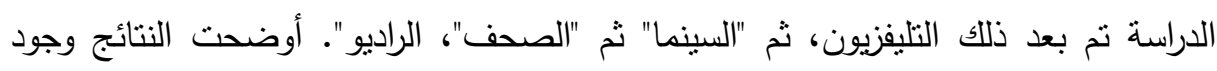

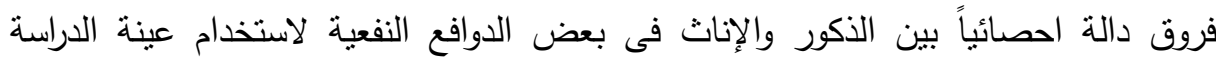

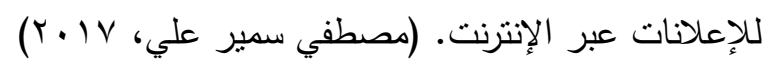

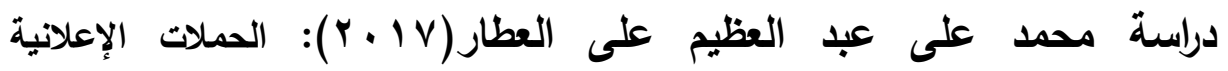
التليفزيونية لمستشفى سرطان الأطفال فى مصر وتأثيراتها عليهم. هدفت هذه الدراسة إلى رصد وتوصيف وتحليل كيفى للحملات الإعلانية التليفزيونية

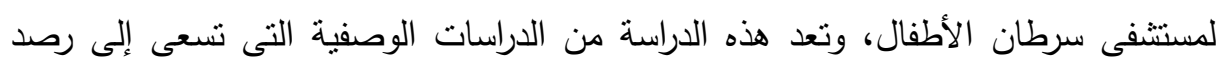

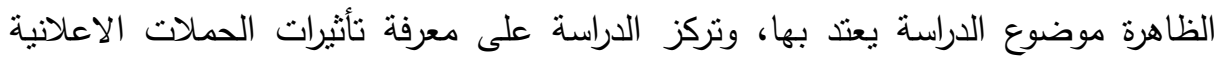
التليفزيونية لمستتفى سرطان الأطفال فى مصر على الأطفال الرضى وضى.

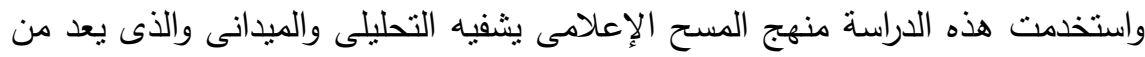
أنسب المناهج ملائمة، ويرتبط ارتباطاً وثيقا بكل من موضوع هذه الاعلها الدراسة وأهدافها.

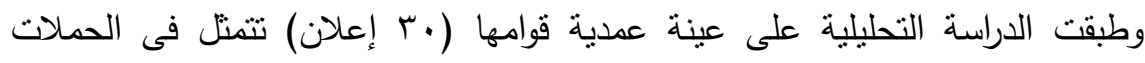
الإعلانية وعينة الدراسة الميدانية وذلك على عينة مناحة من الأطفال مرضى السرطان قوامها

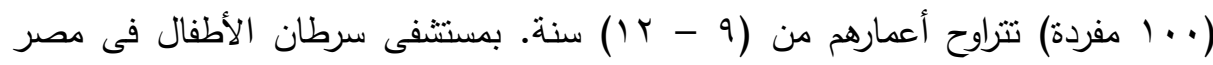


واعتددت الدراسة على مجموعة من الأدوات (استمارة تحليل المضمون - استمارة الاستبيان دليل المقابلة المتعقة) كأسلوب لجمع البيانات في هذه هذه الدراسة.

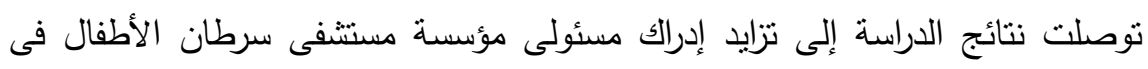

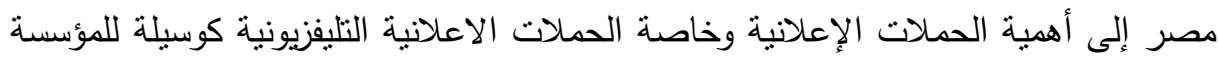

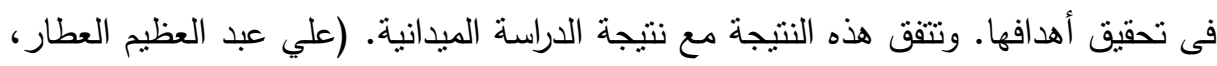
.$(r \cdot) \mathrm{V}$ الاراسات التى تتعلق باستخدام الرسوم المتحركة: دراسة إيمان مصطفي حسن مصطفي الاسوقي(7 1 • ץ): القيم والسلوكيات التي تعكسها المسلسلات الكارتونية ثلاثية الأبعاد وتأثيراتها علي الأطفال.

وهدفت هذة الدراسة إلي التعرف علي القيم التي تعكسها المسلسلات الكارتونية ثلاثية الأبعاد وتأثثراتها علي الأطفال من سن و.9. إنة والتعرف علي القيم الإيجابية والسلوكيات

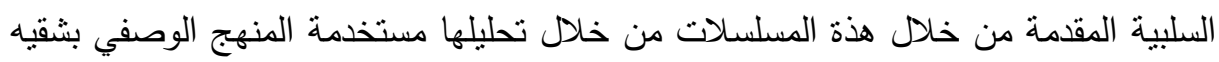
التحليلي والميداني تم تحليل ستة مسلسلات كارتونية ثلاثية الأبعاد هم (سلطة بلدي، القبطان

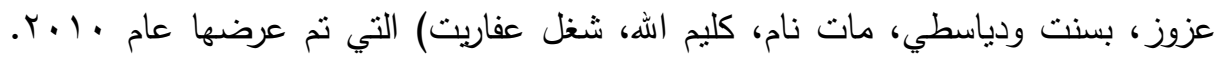

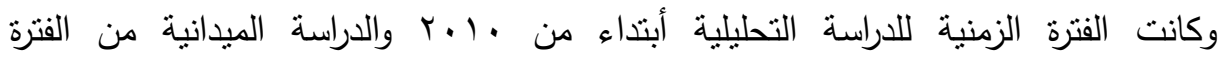

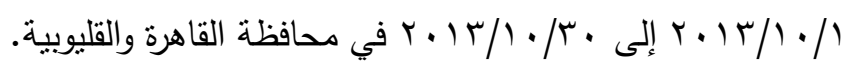

ومن أهم نتائج الدراسة: غلب القالب الب الكوميدي علي معظم المسلسلات الكارتونية ثلاثية

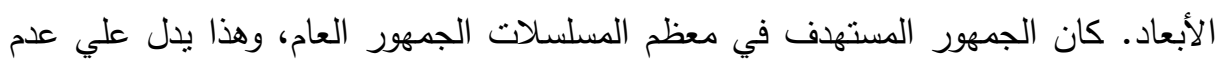
تخصص مسلسلات كارتونية خاصة بالأطفال تناقش مشاكل وقضايا الأطفال. النتائج السلبية

$$
\text { المترتبة علي القيم الإيجابية. }
$$

دراسة مي محب محمود كامل(ع 1 ـ Y): بعنوان علاقة التعرض للكارتون التليفزيوني بانماط السلوك البيئي لدى عينة من الاطفال.

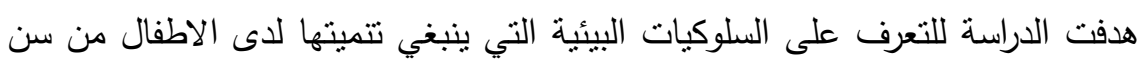

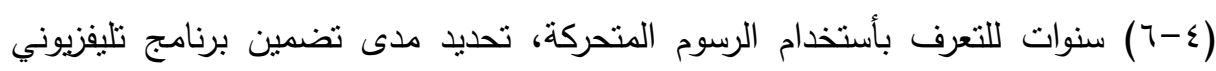

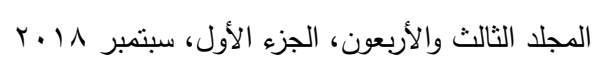


للرسوم المتحركة لهذه السلوكيات البيئية، التعرف على علاقة تعرض الكرتون التليفزيوني

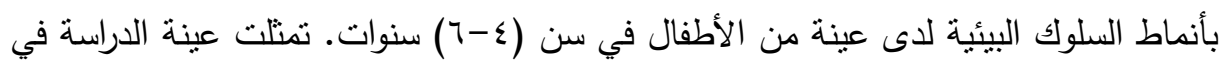

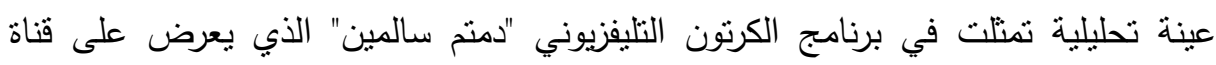
سبيس تون، عينة ميدانية تكونت من •0 طفل من مدرسة مودرن سكول استخدمت الدراسة

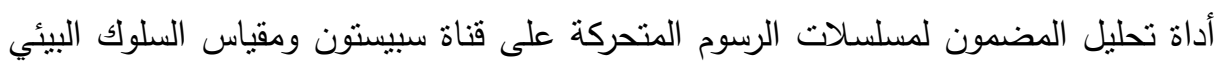
كأداة لجمع البيانات وتوصلت الدراسة إلى أنه لا نوجد فروق ذات ذات دلاتلة لألة إحصائية بين الذكور

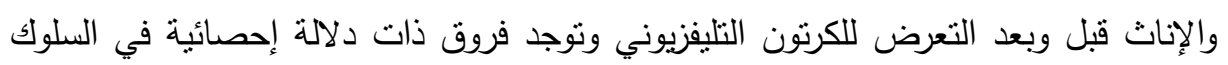
البيئي قبل وبعد التعرض للكرنون التليفزيوني. الدراسات التى تتعلق بالمفاهيم والسلوك البيئى لاى الأطفال: دراسة ثروت فرج خليل إبراهيم(10 ب): وعنوانها: ممارسة الأنثطة الأعلامية وعلاقتها بإكساب طلاب المرحلة الثانية من التعليم الأساسى بعض المفاهيم هيم العلمية والبيئية

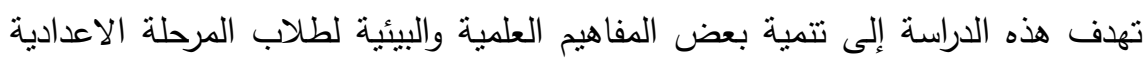

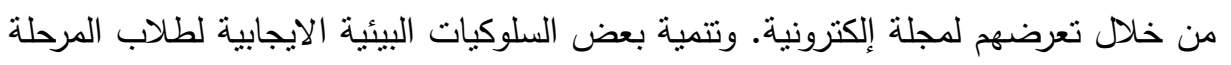

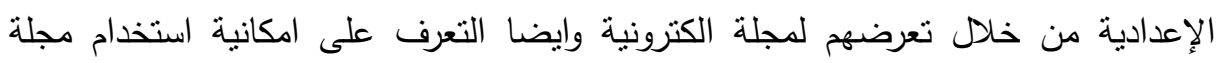

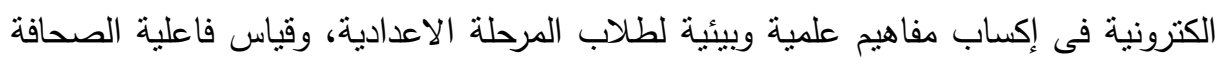
الالكترونية كنشاط إعلامى مدرسى مستحدث فى اكتساب بعض الكفاهيم العلمية والبيئية لطلاب المرحلة الاعدادية والتعرف على درجة اكتساب المفاهيم العلمية والبيئية واجراء المقارنة بين افراد عينة البحث وكذلك الوقوف على درجة رضا المبحوثين حول التصميم التى قدمت بها المفاهيم العلمية والبيئية.

طبقت هذه الدراسة على عينة من التلاميذ وقوامها (... (1) تلميذ وتلميذة من تلاميذ

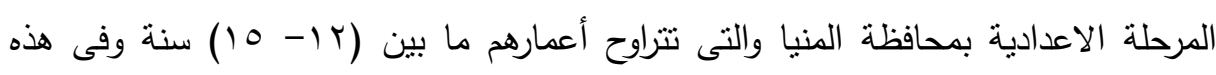

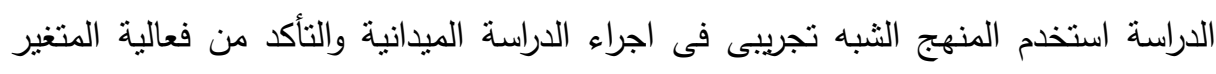
المتغير المستقل. ومعرفة مدى فعالية استخدام الصحافة الأكترونية فى اكتساب المفاهيم العلمية والبيئية لطلاب المرحلة الاعدادية. وأستخدمت أدوات جمع البيانات فى هذه الئه الدراسة أختيار المفاهيم البيئية مقياس السلوكيات البيئية ومقياس درجة الرضا عن المجلة الالكترونية. 
ومن نتائج الدراسة ارتفاع الدرجة الكلية لاكتساب المفاهيم العلمية والبيئية ارتفاع النسبة الى وجود استخدام وسيلة جديدة (المجلة الالكترونية) بما يحتويه من عناصر التفاعلية والجذب التبه والتشويق وتهيئة جو مناسب من خلال اعتماد الصحيفة على مزج مصادر المعرفة بأثكالها المختلفة السمعية والبصرية والمكتوبة مع نوافر امكانية نسجيلها وحفظها وطباعتها مما يزيد من شد انتباه الطالب والاستمرار فى منابعة الصحيفة والاستفادة منها. وارتفاع متوسط درجات طلاب المجموعة التجريبية عن متوسط درجات المجموعة الظابطة فى التطبيق البعدى لأختبار المفاهيم العلمية والبيئية لصالح المجموعة التجريبية. فكانت السخرية في المرنبة

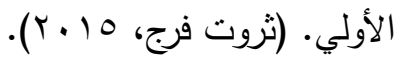

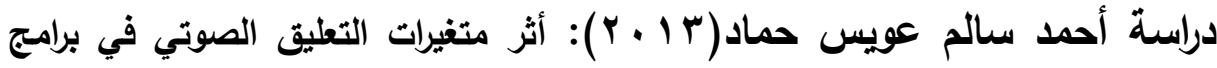
الكبيوتر التعليمية علي تنمية المفاهيم العلمية لطقل الروضة. هدف هذه الدراسة إلى التعرف على أثز متغيرات التعليق الصوتي في برامج الكمبيوتز التعليمية علي تتمية المفاهيم العلمية لطفل الروضة أجريت الدراسة علي مجموعة من الأطفال وتكونت العينة من Vo طفل من أطفال الروضة تم تقسمه إلي ثلاث مجموعة منساوية.

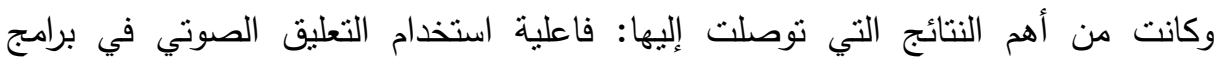
الكمبيوتز التعليمية مع المجموعات التجربية الثلاثة في تتمية المفاهيم العلمية لأطفال الروضة. اثتتت نتائج الدراسة فاعلية البرنامج الكمبيوتري التعليمي المستخدم في تتمية الدفاهيم العلمية للأطفال وهذا يؤكد على فاعلية استخدام برامج الكمبيوتر التعليمي في مرحلة رياض الأطفال.

\section{الإطار النظيه للتوراسة}

تعريف الرسوم المتحركة: هناك عدة تعريفات للرسوم المتحركة منها: تعد الرسوم المتحركة من القوالب الفنية المتميزة التى يعتمد عليها بوصفها فقرات فى برامج الاطفال أو وضعها مواد قائمة بذاتها، حيث أن لها القدرة على جذب انتباه الطفل وتزويده بالمعارف والأفكار بصورة شيقة من خلال مشاهد متكاملة تعتمد على الصوت والصورة والحركة والألوان. 
علاقة الأطفال بالرسوم المتحركة: أصبحت الرسوم المتحركة جزءاً أساسياً من حياة بعض في

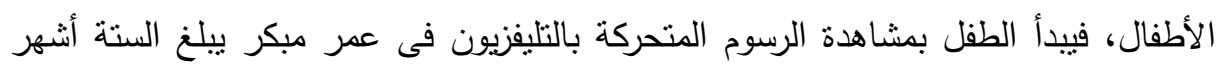

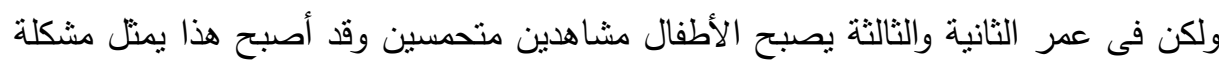

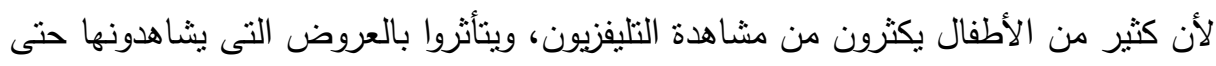

$$
\text { وإن كانت الرسوم المتحركة تتسم بالعنف وتسبب إدمانها. }
$$

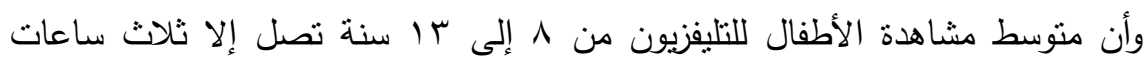

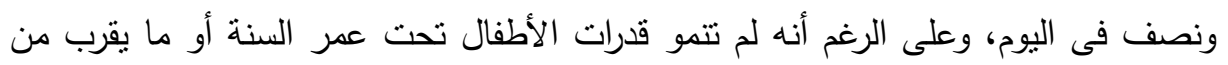
ذلك بشكل كامل لاكتساب المعلومات وترميزها وتتظيمها واستراجاعها. لكن سيظل الأهتمام الأكبر لدى الأطفال هو مشاهدة التليفزيون ومتابعة الأحداث والحلقات المثيرة، فالرسوم المتحركة بها العديد من عوامل حذب النتباه الأطفال كالألوان

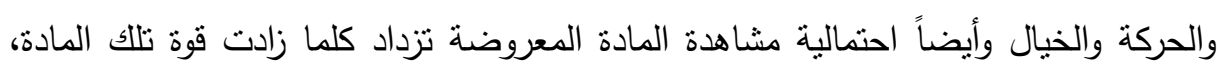
وأن الأطفال يملون أكثر لمشاهدة العروض والمشاهد الإعلامية التى تحتوى على قد كبير من الحركة، والمشحونة بمؤثرات بصرية وصوتية خاصة الاصنة لذلك يتولد الثعور الزائف عن الواقع وهو يشجع الأطفال على محاولة أداء الأثباء التى ودئه يشاهدون أبطالها الخارقين يقومون بها. وهذه الأنواع من أفلام الكارتون تعرض لئل على الألى الأطفال

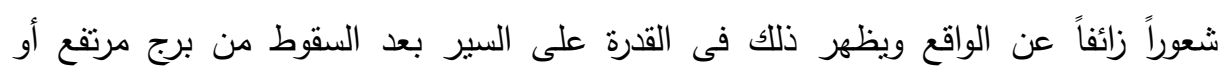

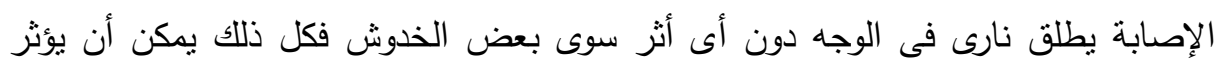

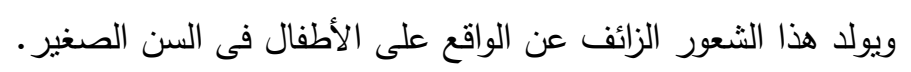

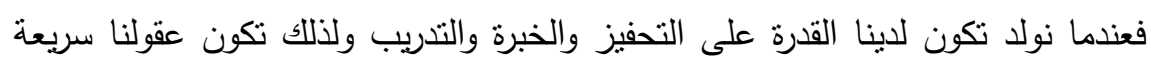
التأثثر إلى حد كبير ومن ثم فإن تتمية عقولنا تعتبر مزيج ديناميكى من الطبيعة والنشأة، لذلك

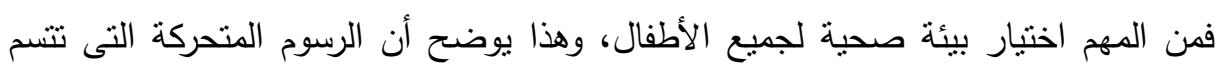
بالعنف غير صحية للأطفال لأن التفاعل مع أى بيئة بوجه عام يعزز تتمية العقل (مارينا

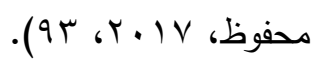


تأثير الرسوم المتحركة على سلوك الأطفال بثكل عام: تعتبر الرسوم المتحركة من أهم المواد

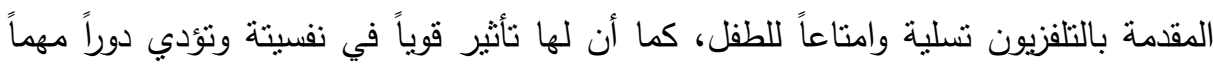

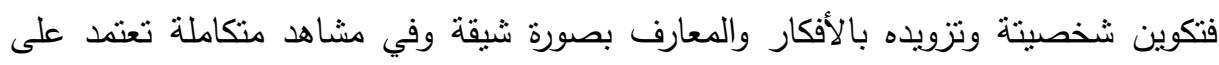

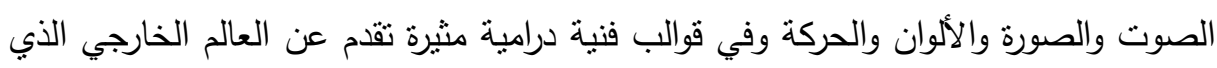

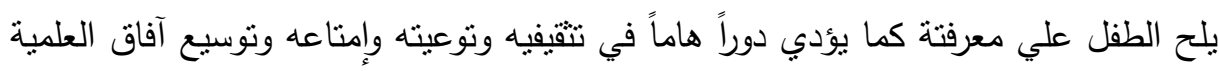
والفكرية وبلورة شخصيته الوجدانية والأجتماعية.

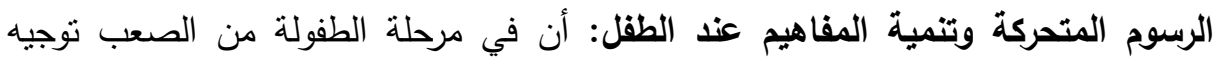

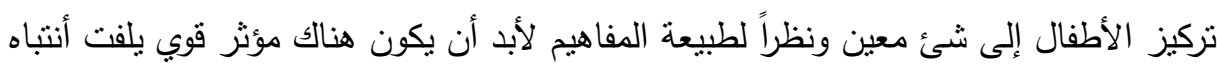

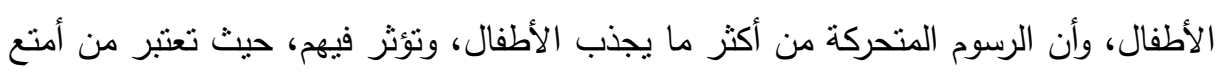

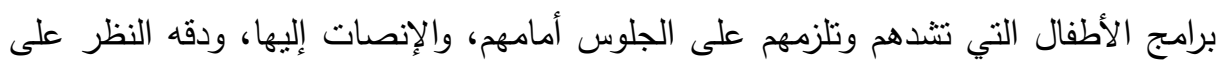

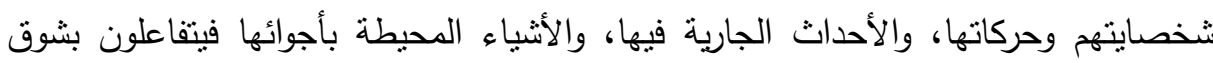
وجدية ويستجييون إلى لغاتها. ولوجود صعوبة في الوصول إلى عقل الطفل لابد من وجود وسيط ينقل الرسالة إلى عقل

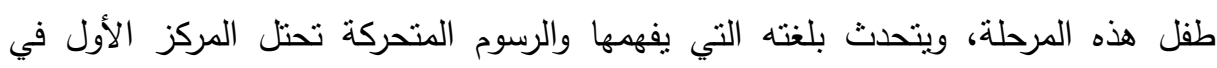

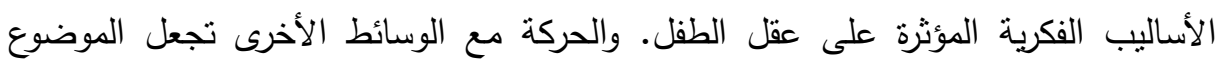

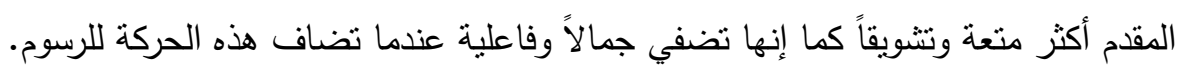

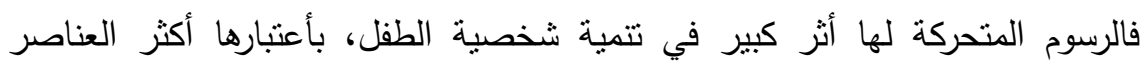

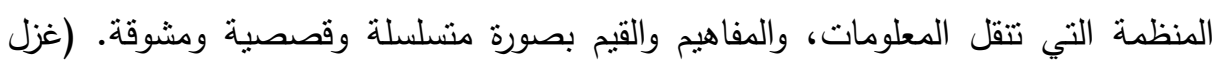

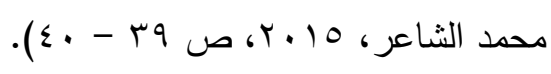
ايجابيات الرسوم المتحركة: تنلخص إيجابيات الرسوم المتحركة فى العناصر التالية:

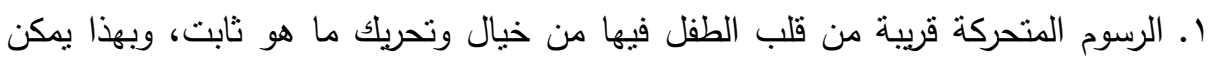

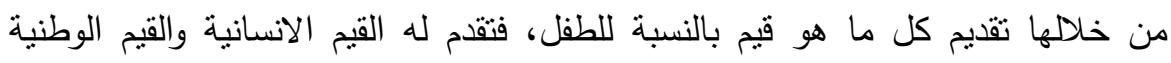
والأخلاقية والثقافية. 
r. تلبى للطفل بعضاً من إحتياجاته النفسية وتتبع له غرائز عديدة مثل حب الاستطلاع حيث يكتثف الجديد يومياً وتتمى لدية غريزة حب المنافسة والمسابقة فتجعله يسعى للنجاح.

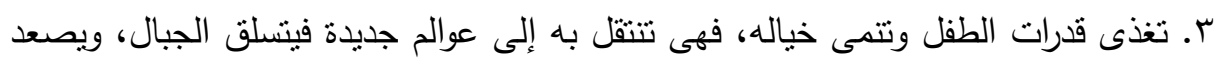
الى الفضاء كما تعلمه اساليب جديدة فى التفكير والسلوك وتنثير إحدى دراسات اليونسكو أن الاطفال يكتسبون العديد من السلوكيات نتيجة تعرضهم الكثيف للبرامج والافلام الكارتونية، ويزداد التأثير كلما زادت ساعات التعرض عن أربع ساعات يومياً.

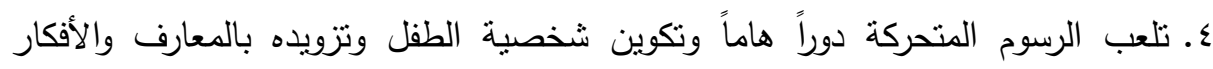

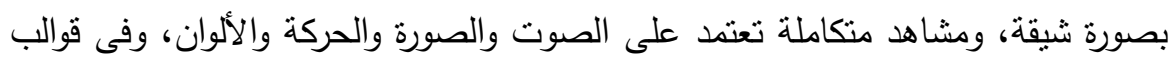

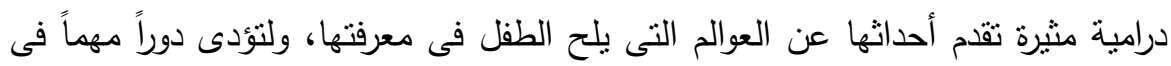
توعية الطفل وتتقيفه وإمتاعه وتوسيع افاقه الفكرية وبلورة شخصيته الاجتماعية والوجدانية. ه. لها دوراً هاماً فى توعية الطفل وتتقيفه وامتاعه وتوسيع أفاقه الفكرية والعلمية وبلورة شخصيته الاجتماعية والوجدانية. T. سهولة تلقى الطفل للمعلومات التى تزيد غرسها فيه والتى تظهر من خلال الافلام التى

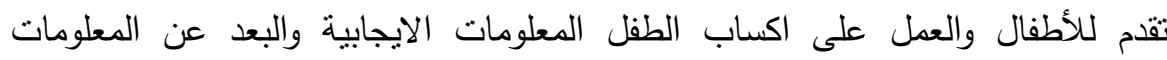
السلبية. سلبيات الرسوم المتحركة: يلجأ قطاع واسع من الاهالى لاشغال اوقات فراغ أطفالهم بمشاهدة

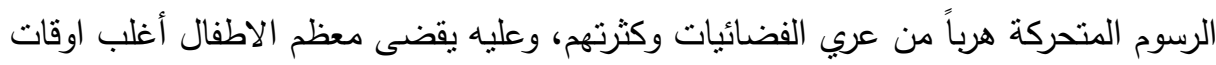

أما عن الآثار السلبية العامية: ا ا ـ زعزعة الأمن ونشر الخوف. r. تركز معظم موضوعات الرسوم المتحركة على العنف والجريمة كوسيلة لاثارة التشويق وإن كانوا بداية يخافون الا انهم يعتادون تدريجياً ثم يأخذون بالاستماع والتقليد.

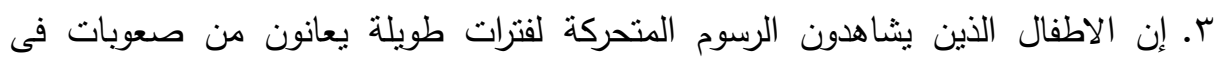

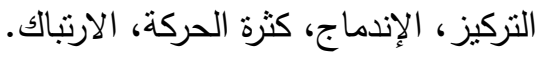


ع. مشاهدة الرسوم المتحركة لفترات طويلة تقلل من عملية الاتصال بينه وبين بيئته

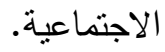

ه. غياب المضامين الاقتصادية المرتبطة بالادخار والعمل والانتاج وترشيد الاستهلاك. ( مي

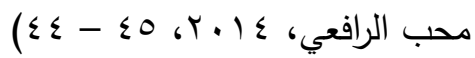

\section{الإجباءايت المنهجية اللكوراسة}

منهج الدراسة: تعد الدراسة من الدراسات الوصفية التحليلية يستخدم فيها منهج المسح بالعينة لثقيه التحليلى والميدانى وايضاً استخدام الثبه تجريبى للتعرف على أثز المتغير

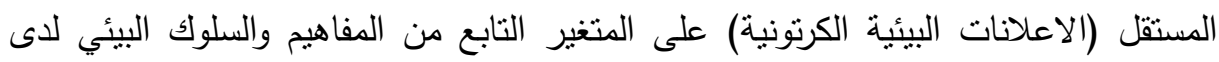
الأطفال ويستخدم التصميم التجريبى للمجموعة التجريبية الواحدة. حدود الدراسة:

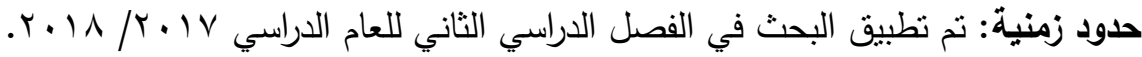
حدود مكانية: نم التطبيق في كل من مدرسة مصطفى كامل الإبتدائية المشتركة (حكومة) ومدارس طلائع المستقبل للغات. عينة البحث:

مجتمع وعينة الاراسة الميدانية:

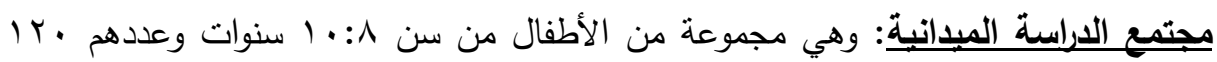
تلميذ وتلميذة.

\begin{tabular}{|c|c|c|c|}
\hline النسبة المئوية & التكرار & المستويات & \\
\hline$\% \leqslant \wedge, r$ & 01 & ذكور & \multirow{3}{*}{ النوع } \\
\hline$\% 01 . V$ & 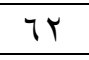 & إناث & \\
\hline$\% 1 \ldots$ & 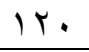 & الإجمالي & \\
\hline$\% 0$. & 7. & حكومى & \multirow{3}{*}{ التعليم } \\
\hline$\% 0$. & 7. & اللغات & \\
\hline$\% 1 \ldots$ & $1 \%$ & الإجمالي & \\
\hline
\end{tabular}
جدول(1) : نوزيع عينة الدراسة وفقاً للمتغيرات الديموجرافية للاراسة

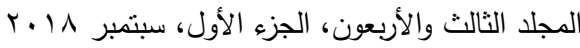




\section{مجتمع وعينة الدراسة التحليلية:}

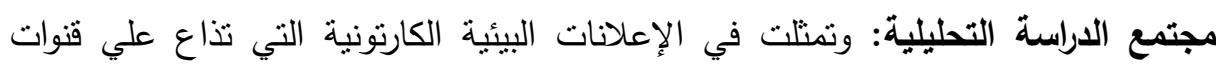

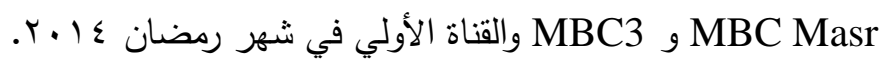

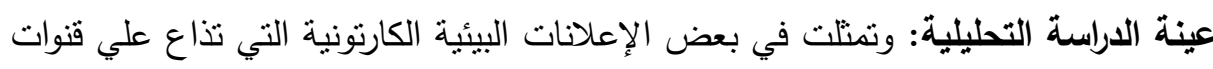
MBC Masr

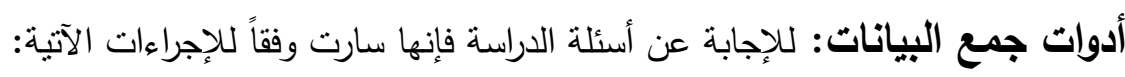

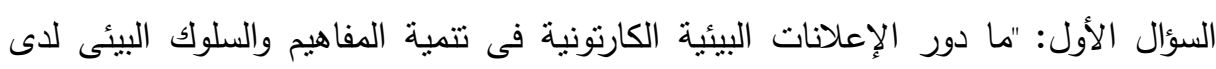
عينة من الأطفال؟" وللإجابة على هذا السؤال نم إعداد استمارة تحليل محتوى (ثكل الإنل

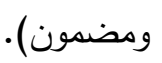
ويشتمل الهذف الاساسي من وضع استمارة تحليل المحتوي علي الوقوف الفعلي لوجود

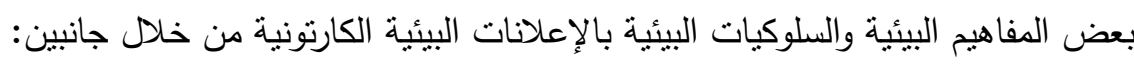

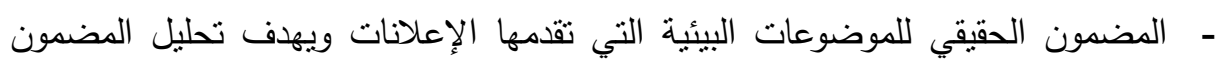

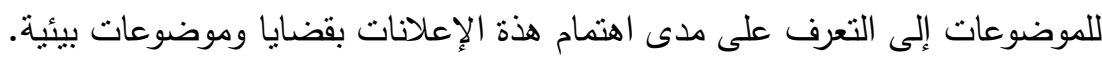
- الثكل الذي تقدم بة تلك الموضوعات من خلال الإعلانات البيئية الكارتونية ويهدف تحليل الإنيل

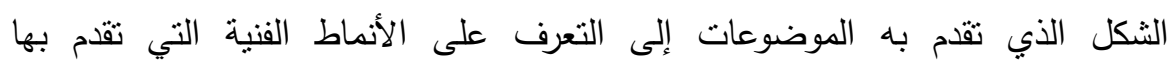

$$
\text { الموضوعات البيئية. }
$$

\section{الصدق والثبات لاستمارة تحليل الثكل المضمون:}

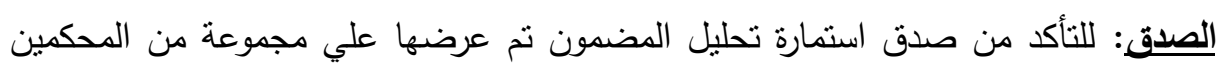

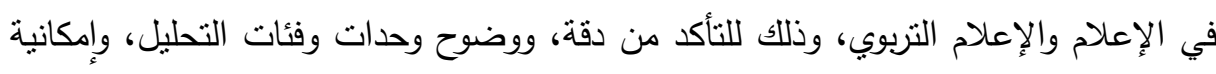

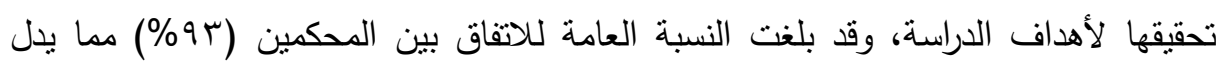

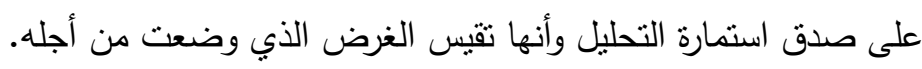

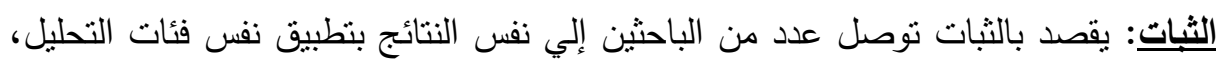
ووحداته علي نفس المضمون. وقد قامت الباحثة بتحليل عينة من الإعلانات عينة الدراسة مرتين بفاصل زمني شهر

$$
\text { واحد بين المرتين وقد اوضحت نتيجة التحليل الآتي: }
$$


تم حساب الثبات باستخدام معامل الاتفاق في المرتين حيث طبقت معادلة "هولستي"

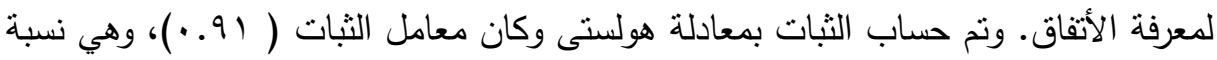
تدل علي ثبات الوحدات، والفئات المستخدمة في تحليل المضمون، كما تعني صلاحية استمارة تحليل الثكل المضمون للنطبيق. • "ما دور الإعلانات البيئية الكارتونية في تتمية المفاهيم البيئية؟" وللإجابة على هذا السؤال تم إعداد اختبار للمفاهيم البيئية مكون (Y^).

صدق اختبار تنمية المفاهيم البيئية: صدق المحكمين: نم عرض المقياس على عدد (V) محكمين من المتخصصين فى دراسات الإعلام والإعلام التربوي والدراسات النفسية والسلوكية للأطفال، ومنهج وطرق التدريس وذللك بغرض دراسة مفردات كل مجال فى ضوء التعريف الإجرائى له، وقد تم الإبقاء على العبارات التى جاءت نسبة اتفاق المحكمين عليها •^^\% فأكثر ، وتم حذف بعض العبارات وتعديل بعضها فى ضوء الملاحظات التى أبداها المحكمين؛ حيث انتهى عدد العبارات إلى (r^) عبارة. - مبار صدق الانساق الاخلي:

جدول(Y): معاملات الارتباط (بيرسون) بين متوسطات اختبار المفاهيم البيئي حيث ن=. ع

\begin{tabular}{|c|c|c|}
\hline معامل الارتباط & عدد العبارات & ابعاد الاختبار \\
\hline. .70 & $\mathrm{~V}$ & البيئة \\
\hline.$\vee \vee \wedge$ & $r$ & الموارد البيئية \\
\hline. .10 & $\wedge$ & التلوث البيئي \\
\hline..$\wedge \Lambda$ & $r$ & إسنتزاف الموارد \\
\hline.$V r$ & $\varepsilon$ & ترشيد استخدام الموارد \\
\hline $.9 \varepsilon$ & $\varepsilon$ & المخلفات واعادة التذوير للمخلفات \\
\hline. .97 & rA & إجمالى الاختبار المفاهيم البيئي \\
\hline
\end{tabular}

يتبين من الجدول السابق إلى تمتع اختبار المفاهيم البيئي بمعاملات ارتباط قوية ودالة

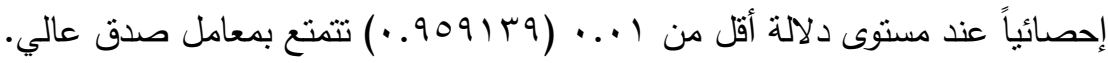


ثبات الاختبار:

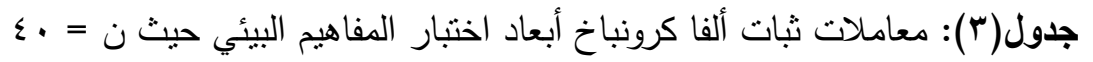

\begin{tabular}{|c|c|c|}
\hline معامل ألفا كرومباخ & عدد العبارات & أبعاد الاختبار \\
\hline. .99 & V & البيئة \\
\hline. .91 & $r$ & الموارد البيئية \\
\hline..$\wedge V$ & $\Lambda$ & التلوث البيئي \\
\hline..$\vee T$ & r & إستتزاف الموارد \\
\hline..$\wedge 1$ & $\varepsilon$ & ترشيد استخدام الموارد \\
\hline..$\vee \wedge$ & $\varepsilon$ & المخلفات واعادة التدوير للمخلفات \\
\hline . & rA & إجمالى الاختبار المفاهيم البيئي \\
\hline
\end{tabular}

يتضح من الجدول أن معاملات الثبات الناتجة دالة عند مستوى البئ ل... مما يشير إلى أن

الاختبار يتمتع بقدر طيب من الثنات.

• ما دور الإعلانات البيئية الكارتونية فى تعليم الطفل السلوك البيئى؟ وللإجابة علي هذا السؤال تم إعداد مقياس للسلوك البيئي مكون من ( • ع) مفردة.

\section{صدق مقياس المصور للسلوك البيئي:}

صدق المحمين: تم عرض المقياس على (V) محكمين من المتخصصين فى دراسات

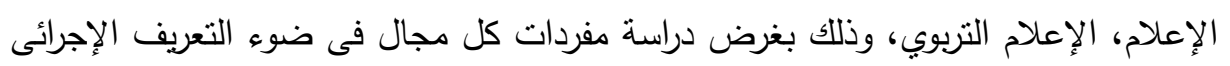

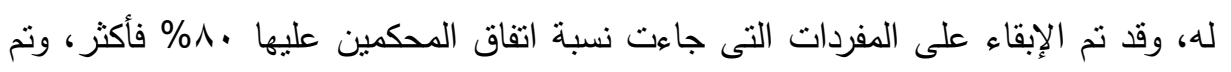

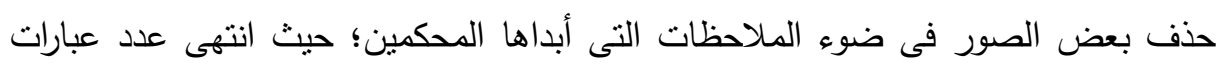

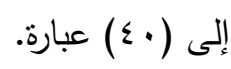




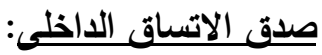
جدول (؛ ): معاملات الارتباط (بيرسون) بين متوسطات المصور للسلوك البيئي حيث ن=. ع

\begin{tabular}{|c|c|c|}
\hline معامل الارتباط & عدد العبارت & المجال \\
\hline \multicolumn{3}{|c|}{ السؤال الأول } \\
\hline$. .7 \leq$ & $\mathrm{V}$ & سلوكيات تجاه النظافة والطريق العام \\
\hline.$\wedge \varepsilon$ & 7 & سلوكيات تجاه المياه والكهرباء \\
\hline. .01 & $r$ & سلوكيات تجاه النباتات والحيوانات \\
\hline..$\wedge r$ & $r$ & سلوكيات تجاه الطعام وترشيده وتلوث الغذاء \\
\hline.$\vee v 7$ & 1 & سلوكيات تجاه عدم إنلاف الأشياء \\
\hline $.7 \mathrm{~V}$ & 1 & سلوكيات تسبب الضوضاء \\
\hline \multicolumn{3}{|c|}{ السؤال الثاني } \\
\hline..$V Y$ & $\varepsilon$ & سلوكيات تجاه النظافة والطريق \\
\hline .0 & $r$ & سلوكيات المسببة لتلوث المياه والهواء \\
\hline. $.0 \mathrm{~V}$ & 1 & سلوكيات نسبب الضوضاء \\
\hline $.0 \leq$ & $\varepsilon$ & سلوكيات تجاه الحيوانات والنباتات \\
\hline. .70 & 0 & سلوكيات اتجاه الإسراف في الكهرباء والمياه \\
\hline.$v r$ & 1 & سلوكيات تجاه إعادة التدوير \\
\hline \multicolumn{3}{|c|}{ السؤال الثالث } \\
\hline. .19 & 1 & سلوكيات اتجاه الحيوانات \\
\hline. $.9 \varepsilon$ & $\varepsilon$ & إجمالي مقياس المصور للسلوك البيئي \\
\hline
\end{tabular}

يتبين من الجدول السابق إلى تمتع مقياس المصور للسلوك البيئي بمعاملات ارتباط قوية

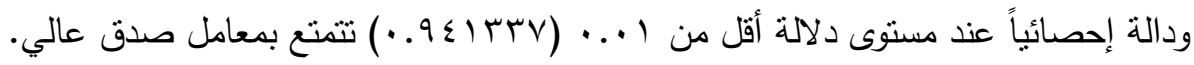
ثبات مقياس المصور للسلوك البيئي:

تم حساب ثبات المقياس المصور للسلوك البيئي باستخدام طريقة كرونباخ (معامل ألفا):

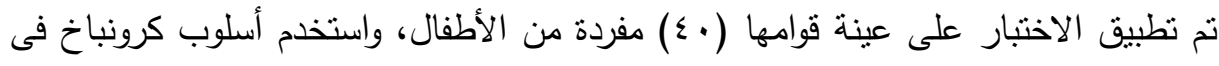
التحقق من ثبات الاختبار، وفيما يلى جدول يوضح ما تم النوصل إليه من نتائج فى هذا 
جدول(ه): معاملات ثبات ألفا كرونباخ لمقياس المصور للسلوك البيئي

\begin{tabular}{|c|c|c|}
\hline معامل الارتباط & عدد العبارت & المجال \\
\hline \multicolumn{3}{|c|}{ السؤال الأول } \\
\hline. .11 & v & سلوكيات تجاه النظافة والطريق العام \\
\hline. $.9 \varepsilon$ & 7 & سلوكيات تجاه المياه والكهرباء \\
\hline$. .7 \leq$ & $r$ & سلوكيات تجاه النباتات والحيوانات \\
\hline. .07 & $r$ & سلوكيات تجاه الطعام وترشيده وتلوث الغذاء \\
\hline..$V T$ & 1 & سلوكيات تجاه عدم إتلاف الأشياء \\
\hline.. $\mathrm{Vo}$ & 1 & سلوكيات نسبب الضوضاء \\
\hline \multicolumn{3}{|c|}{ ل السؤال الثاني } \\
\hline. .17 & $\varepsilon$ & سلوكيات تجاه النظافة والطريق \\
\hline. .19 & $r$ & سلوكيات المسببة لتلوث المياه والهواء \\
\hline..$\wedge \Lambda$ & 1 & سلوكيات نسبب الضوضاء \\
\hline..$\vee \wedge$ & $\varepsilon$ & سلوكيات تجاه الحيوانات والنباتات \\
\hline$. .9 \leq$ & 0 & سلوكيات اتجاه الإسراف في الكهرباء والمياه \\
\hline.$v 1$ & 1 & سلوكيات تجاه إعادة التدوير \\
\hline \multicolumn{3}{|c|}{ ل السؤال الثالث } \\
\hline. $.9 \mathrm{~V}$ & 1 & سلوكيات اتجاه الحيوانات \\
\hline. $.9 \mathrm{~V}$ & $\varepsilon$. & مقياس المصور للسلوك البيئي \\
\hline
\end{tabular}

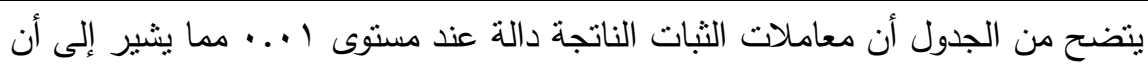
المقياس يتمتع بقدر طيب من الثبات. أساليب المعالجة الإحصائية: تمت معالجة البيانات باستخدام الحاسب الآلي وذلك عن بنّات

Statistical Package for the طريق برنامج المعالجة الإحصائية للعلوم الاجتماعية Social Sciences (SPSS20)

$$
\text { ا ـ المتوسطات الحسابية والانحرافات المعيارية. }
$$

r r حساب اختبار" ت" t-test لمجموعتين مستقلنين (غير مرنبطة) للتأكد من دلالة الفروق الإحصائية بين المجموعة التجريبية قبل التطبيق وبعد النطبيق. r. حساب اختبار" ت" t-test لمجموعنين غير مستقلتين (مرتبطنتين) للتأكد من دلالة الفروق الإحصائية بين المجموعة التجريبية على التطبيق القبلى والبعدى. 
ع. استخدام معامل ارتباط بيرسون Pearson Correlation للتحقق من صدق الاتساق الداخلى للمقياس. 0. معامل ألفا كرونباج للتأكد من ثبات المقياس.

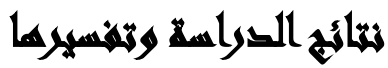

النتائج الخاصة باختبار تنمية المفاهيم البيئية: الفرض الأول: يوجد فرق دال إحصائياً بين درحات أطفال المجموعة التجريبية قبل التعرض

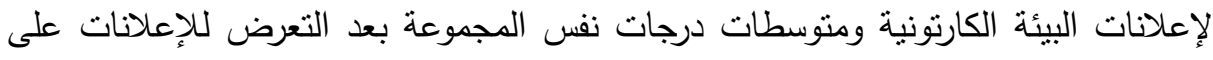
اختبار تتمية المفاهيم البيئية لصالح التطبيق البعدي. تم حساب المتوسطات والانحرافات المعيارية وقيم (ت) بين منوسطي درجات أطفال المجموعة التجريبية قبل وبعد التعرض للإعلانات البيئية الكارتونية كما يتضح فى الجدول التالي. جدول (†): نتائج اختبار (ت) T-test لدلالة الفروق بين متوسطات درجات أطفال المجموعة التجريبية قبل وبعد التعرض للإعلانات البيئية الكارتونية

\begin{tabular}{|c|c|c|c|c|c|c|c|}
\hline مستوى الدلالة & الفروق & الحرية & قيمة ت & الانحراف & المتوسط & عدد & التطبيق \\
\hline \multirow{2}{*}{ دالة ** } & \multirow{2}{*}{$\cdots 1$} & \multirow{2}{*}{ YrA } & \multirow{2}{*}{$\varepsilon 1 . v r$} & r. $\varepsilon \varepsilon$ & V.A9 & $K$ IT. & قبلي \\
\hline & & & & $r . \leqslant 9$ & $r \leq \ldots \wedge$ & Ir. & بعدي \\
\hline
\end{tabular}

تتشير نتائج اختبار "ت" فى الجدول السابق إلى وجود فرق دال إحصائباً بين منوسطات

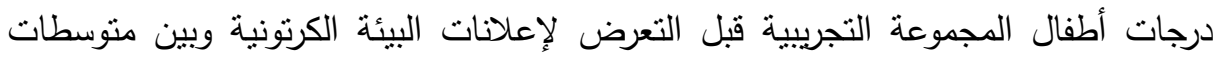
درجات نفس المجموعة بعد التعرض لنلك الإعلانات على اختبار المفاهيم البيئية لصالح

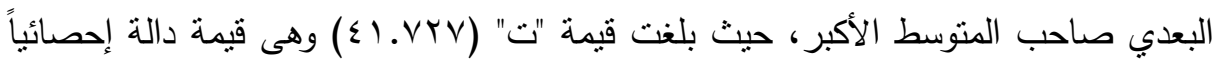

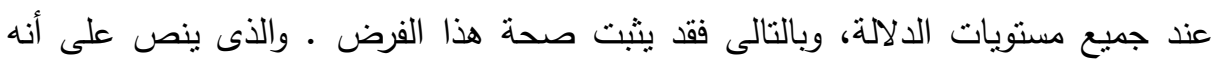

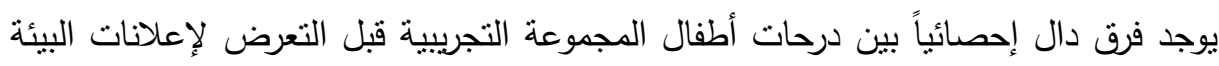


الكارتونية ومنوسطات درجات نفس المجموعة بعد التعرض للإعلانات على اختبار تتمية المفاهيم البيئية لصالح التطبيق البعدي. الفرض الثاني: لا يوجد فرق دال إحصائياً بين متوسطات درحات الذكور ومتوسطات درجات لاتئي الإناث على اختبار تتمية المفاهيم البيئية بعد التعرض للإعلانات البيئية الكارتونية.

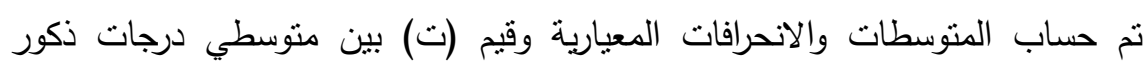
ومتوسطات درجات الإناث على اختبار تتمية المفاهيم البيئية بعد التعرض للإعلانات البيئية لئية الكارتونية كما يتضح فى الجدول التالي. جدول (V): نتائج اختبار (ت) T-test لدلالة الفروق بين منوسطات درجات الذكور ومتوسطات درجات الإناث بعد التعرض للإعلانات البيئية الكارتونية

\begin{tabular}{|c|c|c|c|c|c|c|c|}
\hline مستوى & الفروق & الحرية & قيمة ت & المعياري & المتوسط & عدد & التطبيق \\
\hline \multirow{2}{*}{ غالة } & \multirow{2}{*}{. .091} & \multirow{2}{*}{111} & \multirow{2}{*}{. OrN10 } & Y. $\leqslant 0$ & rr.90 & $0 \wedge$ & ذكور \\
\hline & & & & r.or & $r \varepsilon .19$ & $7 r$ & إناث \\
\hline
\end{tabular}

تشير نتائج اختبار "ت" فى الجدول السابق إلى عدم وجود فرق دال إحصائياً بين متوسطات درجات الذكور وبين متوسطات درجات الإناث بعد التعرض للإعلانات البيئة

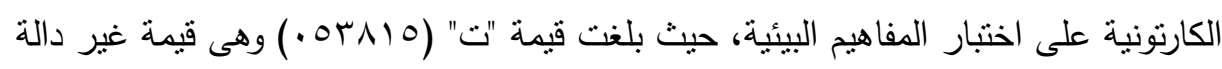

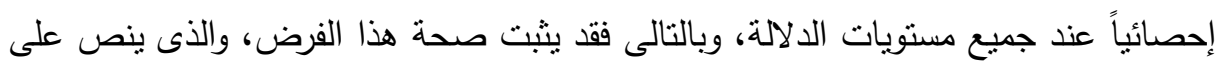
أنه لا يوجد فرق دال إحصائياً بين متوسطات درحات الذكور ومتوسطات درجات الإناث على لئى

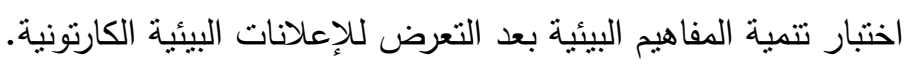

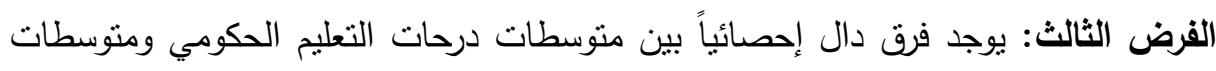
درجات التعليم اللغات على اختبار تتمية المفاهيم البيئية بعد التعرض للإعلانات البيائية دئية الكارنونية لصالح التعليم اللغات.

تم حساب المتوسطات والانحرافات المعيارية وقيم (ت) بين منوسطي درجات التعليم

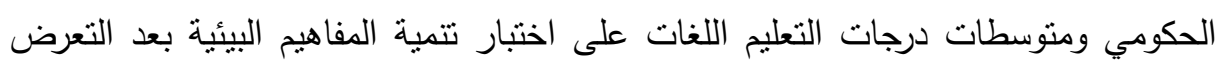
للإعلانات البيئية الكارتونية كما يتضح فيطى الجدول التالي. 
جدول(^): نتائج اختبار (ت) T-test لدلالة الفروق بين متوسطات درجات التعليم الحكومي ومتوسطات درجات التعليم اللغات بعد التعرض للإعلانات البيئية الكارتونية

\begin{tabular}{|c|c|c|c|c|c|c|c|}
\hline مستوى الدلالة & الفروق & الحرية & قيمة ت & الانحراف & المتوبط & عدد & التطبيق \\
\hline \multirow{2}{*}{ دالة* * } & \multirow{2}{*}{$\cdots+1$} & \multirow{2}{*}{111} & \multirow{2}{*}{ r.r. } & r...q & r.r.A. & 7. & حكومي \\
\hline & & & & r.01 & re.or & 7. & اللغات \\
\hline
\end{tabular}

تشير نتائج اختبار "ت" فى الجدول السابق إلى وجود فرق دال إحصائياً بين متوسطات درجات التعليم الحكومي وبين منوسطات درجات التعليم اللغات بعد التعرض للإعلانات التئن البيئة

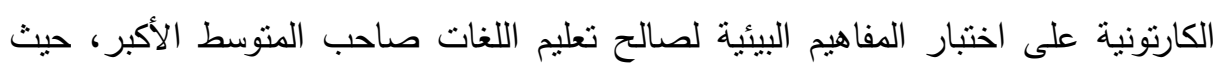

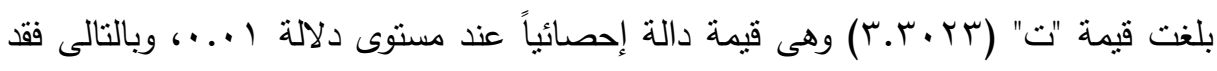

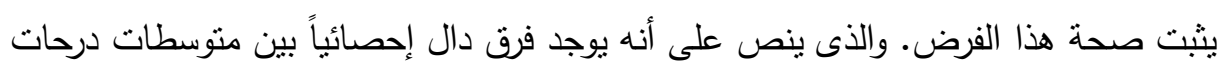

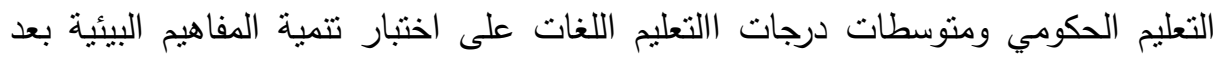
التعرض للإعلانات البيئية الكارتونية لصالح التعليم اللغات. النتائج الخاصة بمقياس السلوك البيئي المصور:

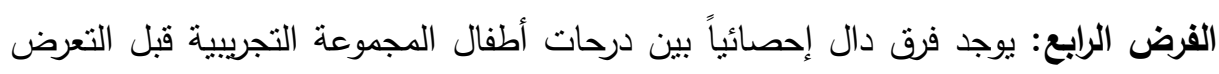

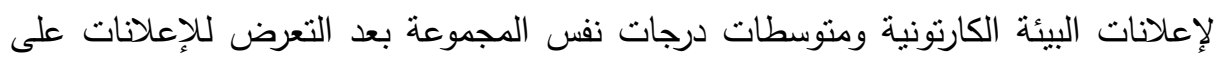
مقياس السلوك البيئي المصور لصالح التطبيق البعدي. تم حساب المنوسطات والانحرافات المعيارية وقيم (ت) بين منوسطي درجات أطفال المجموعة التجريبية قبل وبعد التعرض

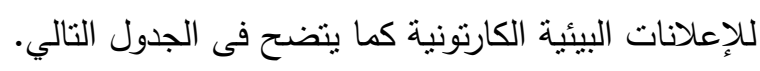

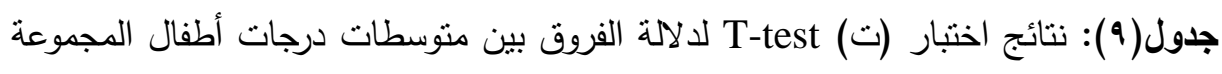
التجريبية قبل وبعد التعرض للإعلانات البيئية الكارتونية

\begin{tabular}{|c|c|c|c|c|c|c|c|}
\hline الدلالة & الفروق & الحرية & قيمة ت & المعياري & المتوسط & عدد & لتطبيق \\
\hline \multirow{2}{*}{ دالة ** } & \multirow{2}{*}{$\ldots 1$} & \multirow{2}{*}{ r } & \multirow{2}{*}{$\Lambda \cdot . r \cdot V$} & T.71 & A.V. & ir. & قبلي \\
\hline & & & & $1.0 r$ & ד. ו. & ir. & بعدي \\
\hline
\end{tabular}


تتشير نتائج اختبار "ت" فى الجدول السابق إلى وجود فرق دال إحصائياً بين متوسطات درجات أطفال المجموعة التجريبية قبل التعرض لإعلانات البيئة الكرتونية وبين متوسطات درجات نفس المجموعة بعد التعرض لتلك الإعلانات على مقياس السلوك البيئي المصور

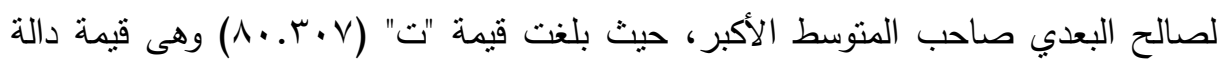

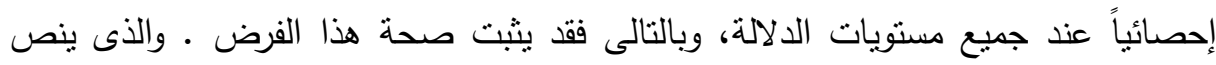

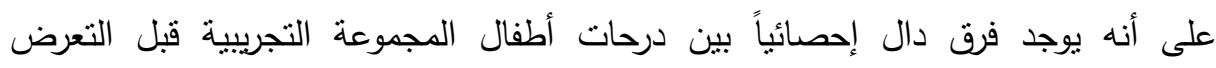

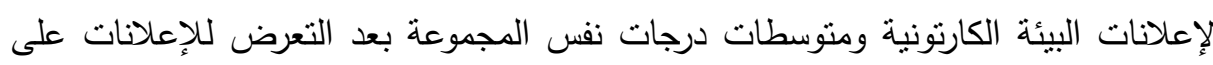
مقياس السلوك البيئي المصور لصالح التطبيق البعدي. الفرض الخامس: يوجد فرق دال إحصائياً بين متوسطات درحات الذكور ومتوسطات درجات الإناث على مقياس السلوك البيئي المصور بعد التعرض للإعلانات البيئية الكارتونية. تم حساب المتوسطات والانحرافات المعيارية وقيم (ت) بين متوسطي درجات ذكور لتوري ومتوسطات درجات الإناث على مقياس السلوك البيئي المصور بعد التعرض للإعلانات البيئية الكارتونية كما يتضح فى الجدول التالي. جلول (·1): نتائج اختبار (ت) T-test لدلالة الفروق بين منوسطات درجات الذكور ومنوسطات درجات الإناث بعد التعرض للإعلانات البيئية الكارتونية

\begin{tabular}{|c|c|c|c|c|c|c|c|}
\hline الالالة & الفروق & الحرية & قيمة ت & الالمعياري & المتوسط & عدد & التطبيت \\
\hline \multirow{2}{*}{ غيلة } & \multirow{2}{*}{. .091} & \multirow{2}{*}{111} & \multirow{2}{*}{ r.or } & 1.04 & $\mu_{1}$ & 01 & ذكور \\
\hline & & & & $1 . \leqslant 1$ & 11.79 & TY & إناث \\
\hline
\end{tabular}

تشير نتائج اختبار "ت" فى الجدول السابق إلى عدم وجود فرق دال إحصائياً بين متوسطات درجات الذكور وبين متوسطات درجات الإناث بعد التعرض للإعلانات البيئة

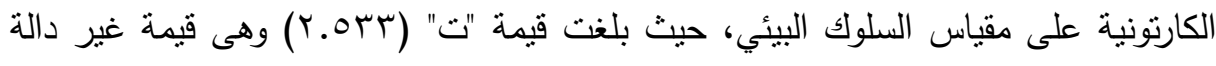

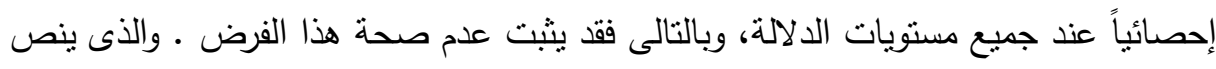
على أنه يوجد فرق دال إحصائياً بين متوسطات درحات الذكور ومنوسطات درجات وبات الإنات لإناث على مقياس السلوك البيئي المصور بعد التعرض للإعلانات البيئية الكارتونية. 
الفرض السادس: يوجد فرق دال إحصائياً بين منوسطات درحات التعليم الحكومي ومتوسطات درجات التعليم اللغات على مقياس السلوك البيئي المصور بعد التعرض للإعلانات البيئية الكارتونية لصالح تعليم اللغات.

تم حساب المتوسطات والانحرافات المعيارية وقيم (ت) بين منوسطي درجات التعليم

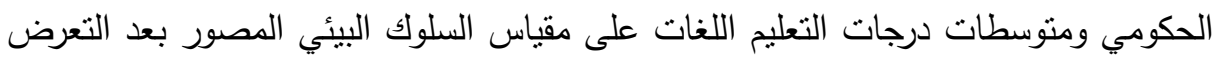

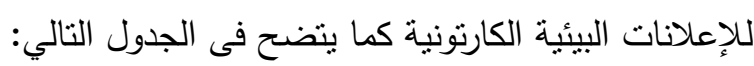

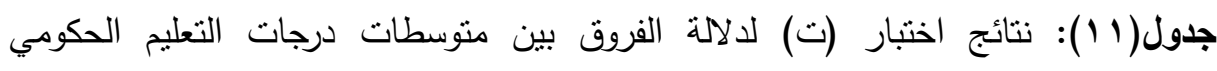

ومتوسطات درجات التعليم اللغات بعد التعرض للإعلانات البيئية الكارتونية

\begin{tabular}{|c|c|c|c|c|c|c|c|}
\hline مستوى الدلاية & الفروق & الحرية & قيمة ت & الالمعراف & المتوسط & عدد & التطبيق \\
\hline \multirow{2}{*}{ دالة * * } & \multirow{2}{*}{. .001} & \multirow{2}{*}{111} & \multirow{2}{*}{ Г. . V } & Y.1T & rV.VA & 7. & حكومي \\
\hline & & & & Y.AT & ะ9.7r & 7. & اللغات \\
\hline
\end{tabular}

تتير نتائج اختبار "ت" فى الجدول السابق إلى وجود فرق دال إحصائياً بين منوسطات

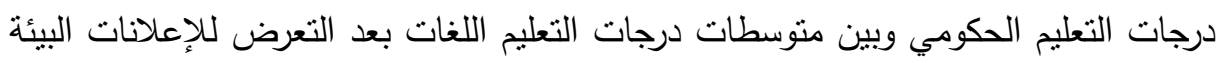

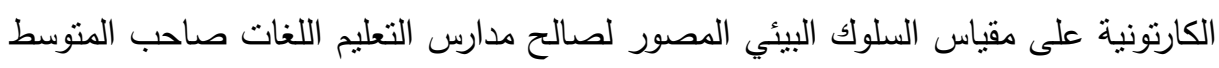

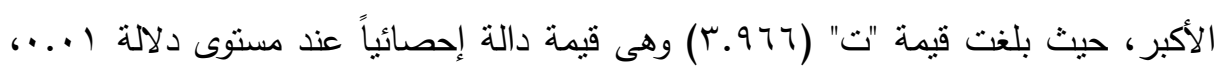
وبالتالى فقد يثبت صحة هذا الفرض. والذى ينص على أنه يوجد فرق دال إحصائياً بين

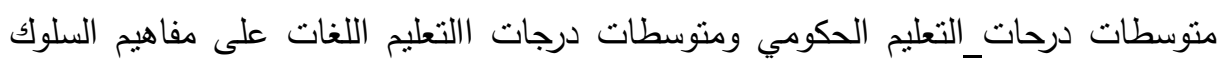
البيئي المصور بعد التعرض للإعلانات البيئية الكارنونية لصالح تعليم اللغات.

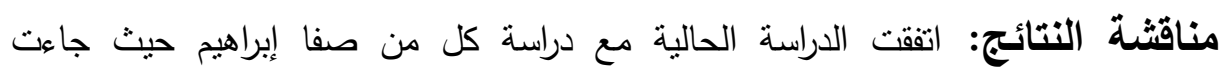

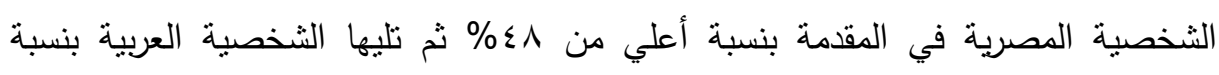

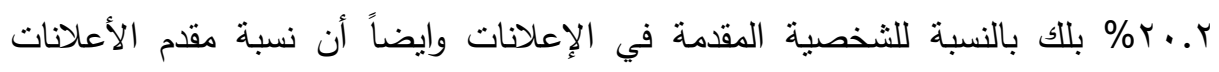

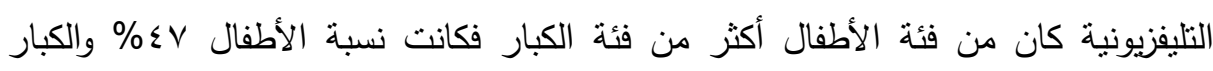

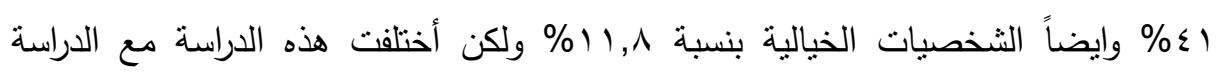
الحالية في سيطرت الإعلانات الخدمية على الإعلانات الكارتونية البيئية عينة الدراسة الحالية

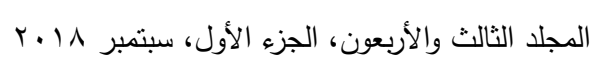


بنسبة (. (1\%)، وذلك لأن تلك الإعلانات حرصت على الترويج لخدمات وليس سلعاً استهلاكية. ولكن في دراسة صفا إبراهيم جاءت نسبة إعلانات السلع أعلي نسبة حيث بلغت الإعات ودات

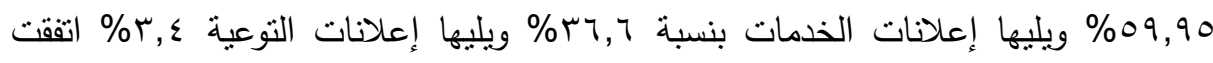

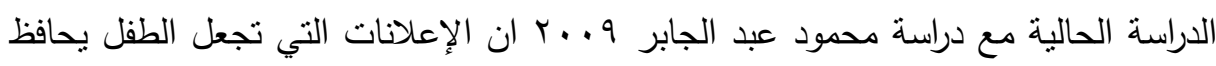

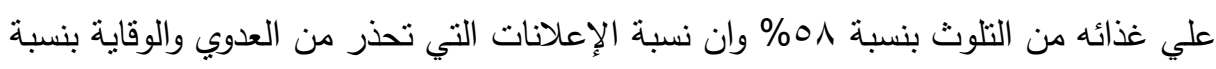
\% ماء مفهوم (الحفاظ على الصحة والوقاية من الأمراض) في صدارة المفاهيم البيئية

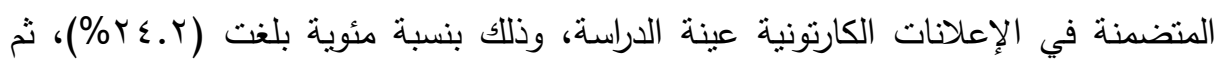

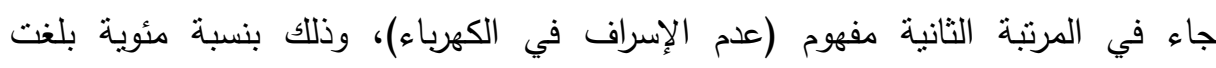

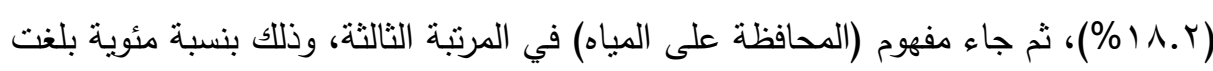

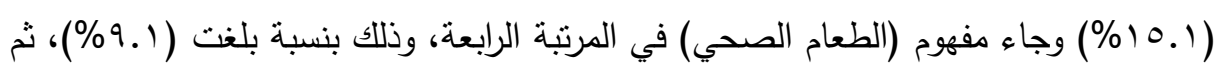

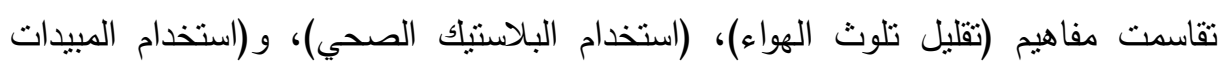

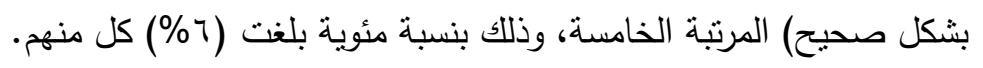

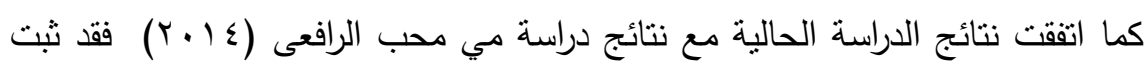
وجود فروق دالة احصائية في السلوك البيئى قبل وبعد التعرض للرسوم المتحركة في التليفزيون

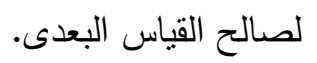

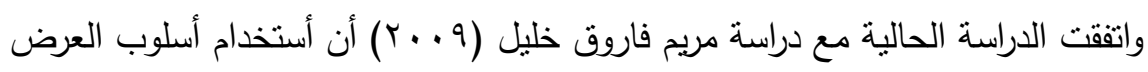

المباشر للمفاهيم الإجتماعية هذا الأسلوب هو السائد في معظم مسلسلات الرسوم المتحركة.

\section{اللحوصياهت}

اكدت نتائج الدراسة الحالية عن أهمية الرسوم المتحركة في تدريس المفاهيم والسلوكيات

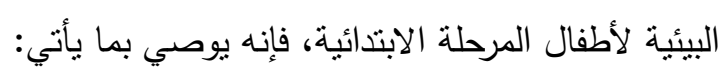
• الأهتمام بتضمين الموضوعات البيئية المناسبة للمرحلة الابتدائية بالاعلانات التلايفزيونية مع الاهتمام بعرض التفاصيل والصور المعبرة عنها. • يمكن من خلال هذا النوع من الإعلانات نشر الدفاهيم البيئية وتعليم السلوك البيئي. 
همكن ان تفيد المعلمين والمعلمات في تعليم الاطفال بعض المفاهيم البيئية والسلوكيات

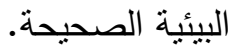

تكثيف انتاج هذا النوع من الاعلانات المقدم في قالب درامي لتفسير وتبسيط المفاهيم وتوضيح السلوكيات الصحيحة التي يجب ان يتبعها الفرد.

مقترحاث الدراسة:

• اجراء المزيد من الدراسات حول آثز استخدام الرسوم المتحركة في تتمية المفاهيم والسلوك البيئي في إطار زماني ومكاني اوسع وقضايا علمية أخري. • ضرورة الاستفادة من الرسوم المتحركة بعمل برامج تربوية لتدريس مختلف المناهج

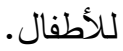
• استخدام الرسوم المتحركة في علاج بعض القضايا الاجتماعية الاخري التي تهدد

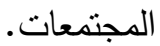

\section{عall}

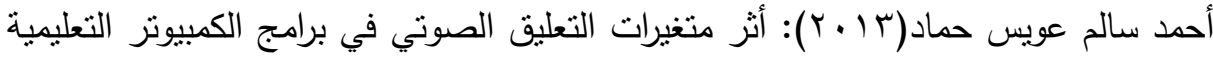

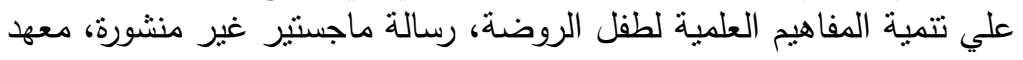
الدراسات والبحوث التربوية، جامعة القاهرة

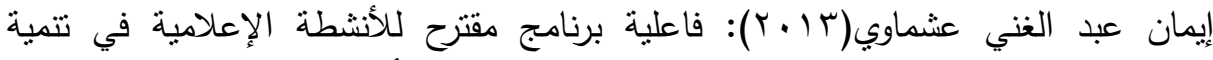

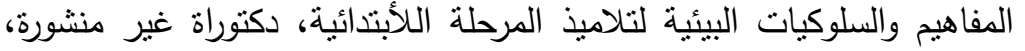

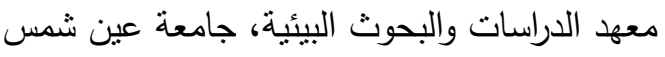

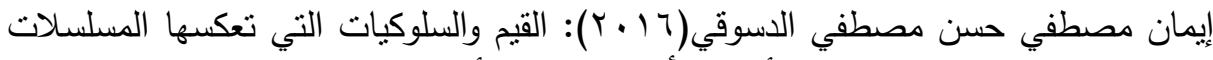

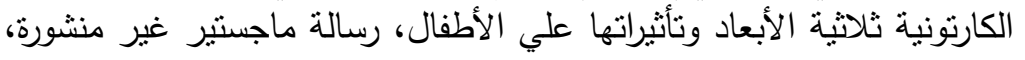

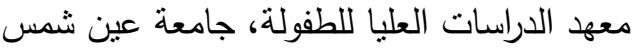

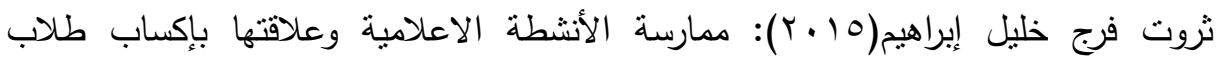

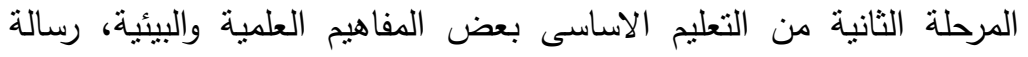
دكتوراه غير منشورة، معهد الدراسات العليا للطفولة، جامعة عين شمس الاسئ

$$
\text { المجلد الثالث والأربعون، الجزء الأول، سبتمبر 1 بـ ب }
$$


حنان عبد المجيد العواك: العنف في الاعلانات التللفزيونية وأثزه علي السلوك العدواني لعينة

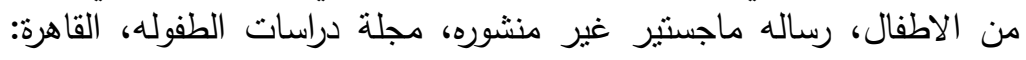

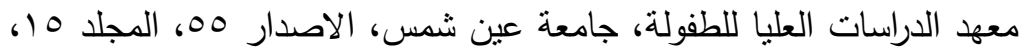

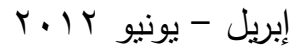

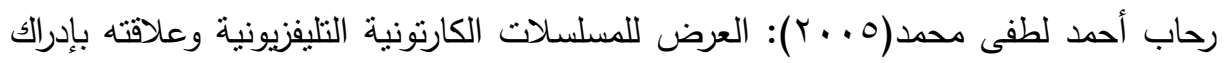

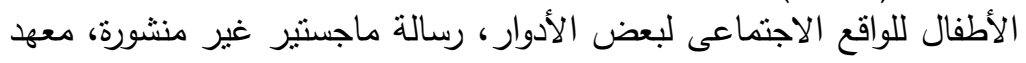

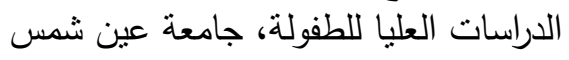

صفا محمد ابراهيم(1) (ب): اخلاقيات الاعلان التليفزيوني وعلاقتها بتتشئة الطفل المصري،

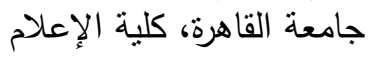

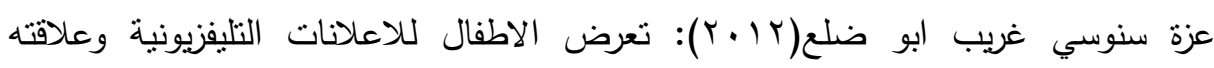

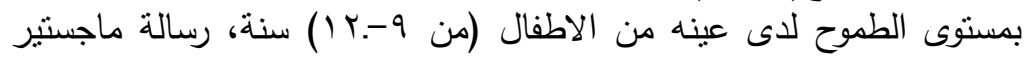
غير منشورة، معهد الدراسات العلبا للطفولة، جامعة عين شمس الطف لهن

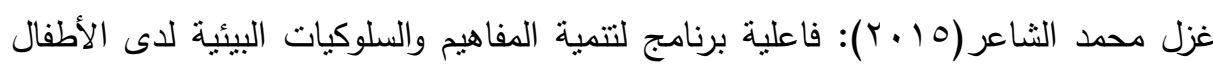

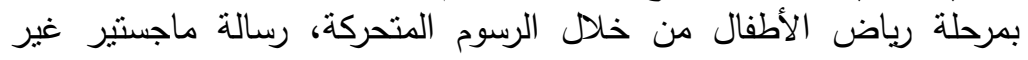

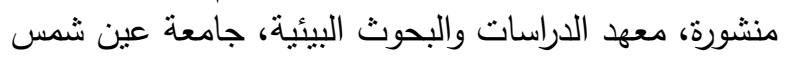

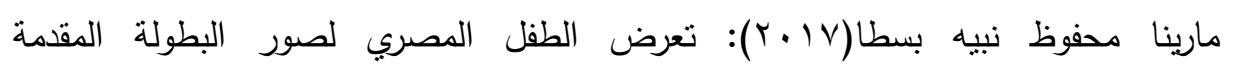

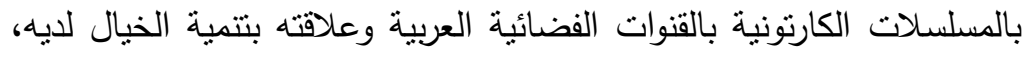

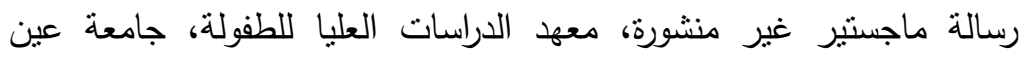
شمس

محب الرافعى: فعالية الألعاب التعليمية فى تتمية الوعى والسلوك البئي لدى اطفال ما قبل

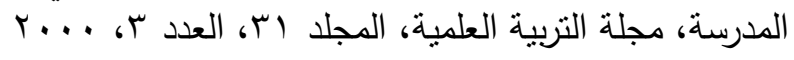

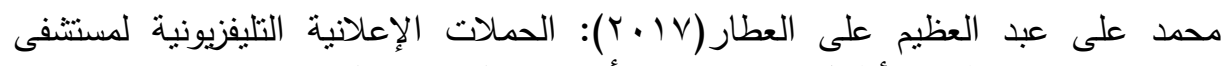

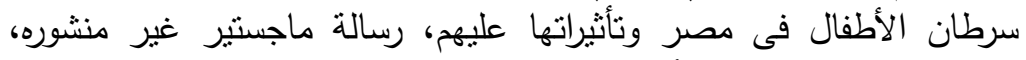

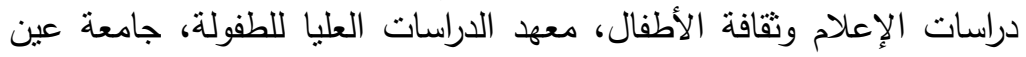

شمس

محمد معوض إبراهيم، عبد الباسط عبد الجليل: دراسات إعلامية جب، القاهرة: دار العلم

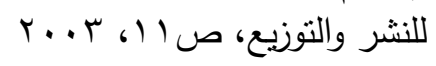

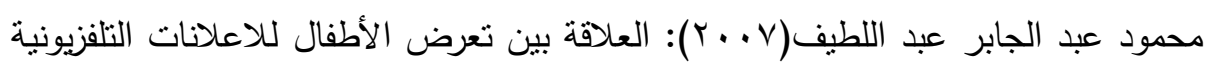

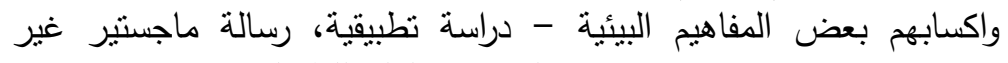
منشورة، جامعة عين شمس، معهد الدراسات العليا للطفولة. 


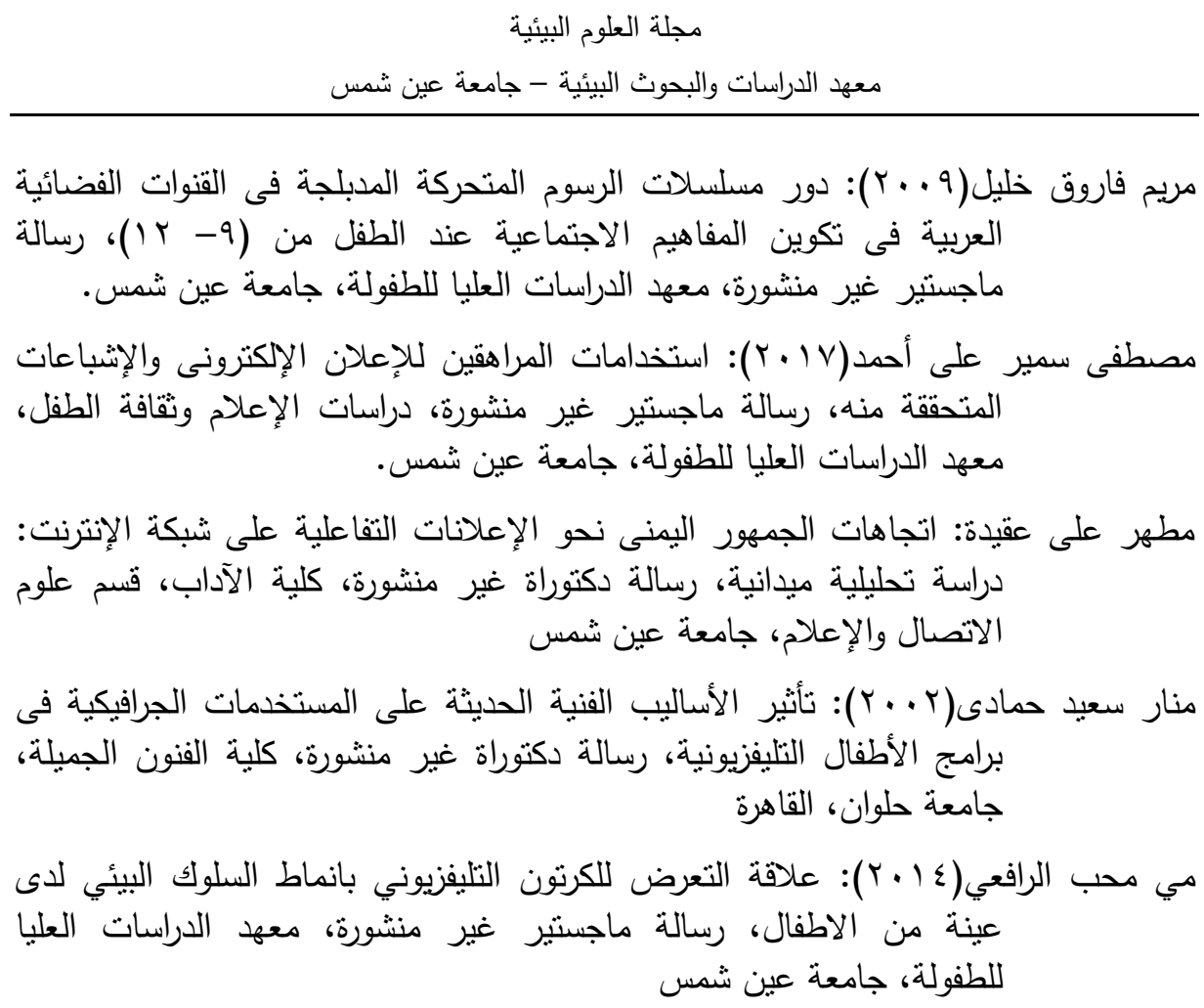

Gregory Fouts; Mitchell Callan; Helly Piasentin; Andrea Lawson: Demonizing in child's television cartoons and Disney Animated Films - Child psychiatry and human development. Vol. 37, Issue 1 (Spr. 2006) PP. 15-23.

Samson, A. and Huber, O.: The interaction of cartoonist's gender and formal features of cartoons. Humor International Journal of Humor Research, Vol. 20, Issue 1 (Feb. 2007), PP. 1-25.

Sandra, L. Calvert: Children as consumers: advertising and Marketing, the future of children.V.18, No.1, Spring 2008 P.206 - 234.

Shaebier, Kirmani and Hafiz UI / Hassen: Children Attitudes towards TV scientific Research, 2008, pp. $693-699$.

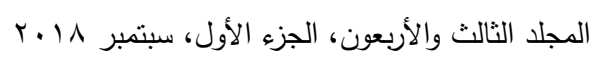


شيماء خيرى عبد البديع وآخرون

\title{
THE ROLE OF ENVIRONMENTAL CARTOON ADVERTISEMENT IN DEVELOPING ENVIRONMENTAL CONCEPTS AND BEHAVIOR IN A SAMPLE OF CHILDREN
}

\author{
Abdel Badee, Shaimaa, K. ${ }^{(1)}$; Al-Qellini, Suzan, Y. ${ }^{(2)}$ \\ and Zedan, Hanan, A. ${ }^{(1)}$ \\ 1) Institute of Environmental Studies and Research, Ain Shams \\ University 2) Faculty of Arts, Ain Shams University
} [17]

\section{ABSTRACT}

This study belongs to the qualitative descriptive - analytical type of studies in which the two-fold sample-survey is used in its analytical and field aspects, using also the quasi-experimental method for identifying the impact of the independent variable on cartoon setting which is the environmental concepts and environmental behavior in a sample of children, using in this, the one-group designing.

This study drives at identifying the role of environmental cartoon advertisements in developing environmental concepts and environmental behavior in a sample of children aged (8-10 yrs. old). The study sample is divided into two samples, the analytical sample represented in some environmental cartoon advertisements displayed on Mbc3 - MBC Masr - The First Channel) channels. It consists of (120) male/female students, divided equally into (60-males and 60 females), selected from Moustafa Kamel Primary Public School and Talaaeh ElMostakbl (Futures Language School). The study uses a content analysis tool of environmental cartoon advertisements, designing the environmental concepts test and scale of pictured environmental behavior as a tool for collecting data.

The study comes to that: there is a significant statistical difference between average scores of male and females on Development of Environmental Concepts Test post exposure to environmental cartoon advertisements.

Keywords: Television Advertisements - Environmental Advertisements - Cartoon Advertisements - Environmental Concepts - Environmental Behavior- Children.

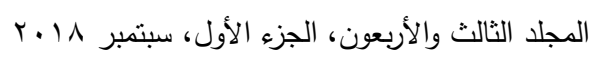

